\title{
Pyridine and phosphonate containing ligands for stable lanthanide complexation. An experimental and theoretical study to assess the solution structure $\uparrow$
}

\author{
Marta Mato-Iglesias, ${ }^{a}$ Edina Balogh, ${ }^{b}$ Carlos Platas-Iglesias, ${ }^{* a}$ Éva Tóth, ${ }^{b, c}$ Andrés de Blas ${ }^{* a}$ and \\ Teresa Rodríguez Blas ${ }^{a}$
}

We report an experimental and theoretical study of the stability and solution structure of lanthanide complexes with two novel ligands containing pyridine units and phosphonate pendant arms on either ethane-1,2-diamine $\left(\mathbf{L}^{2}\right)$ or cyclohexane-1,2-diamine $\left(\mathbf{L}^{3}\right)$ backbones. Potentiometric studies have been carried out to determine the protonation constants of the ligands and the stability constants of the complexes with $\mathrm{Gd}^{\mathrm{III}}$ and the endogenous metal ions $\mathrm{Zn}^{\mathrm{II}}$ and $\mathrm{Cu}^{\mathrm{II}}$. While the stability constant of the $\mathrm{Gd} \mathbf{L}^{2}$ complex is too high to be determined by direct $\mathrm{pH}$-potentiometric titrations, the cyclohexyl derivative $\mathrm{GdL}^{3}$ has a lower and assessable stability $\left(\log K_{\mathrm{GdL}^{3}}=17.62\right)$. Due to the presence of the phosphonate groups, various protonated species can be detected up to $\mathrm{pH} \approx 8 \mathrm{for}$ both ligands and all metal ions studied. The molecular clusters $\left[\mathrm{Ln}(\mathbf{L})\left(\mathrm{H}_{2} \mathrm{O}\right)\right]^{3-} \cdot 19 \mathrm{H}_{2} \mathrm{O}\left(\mathrm{L} \mathrm{n}=\mathrm{La}, \mathrm{Nd}, \mathrm{Ho}\right.$ or $\mathbf{L u}$; $\mathbf{L}=\mathbf{L}^{2}$ or $\left.\mathbf{L}^{3}\right)$ were characterized by theoretical calculations at the HF level. Our calculations provide two minimum energy geometries where the ligand adopts different conformations: twist-wrap $(t w)$, in which the ligand wraps around the metal ion by twisting the pyridyl units relative to each other, and twist-fold $(t f)$, where the slight twisting of the pyridyl units is accompanied by an overall folding of the two pyridine units towards one of the phosphonate groups. The relative free energies of the $t w$ and $t f$ conformations of $\left[\mathrm{Ln}(\mathrm{L})\left(\mathrm{H}_{2} \mathrm{O}\right)\right]^{3-}\left(\mathrm{L}=\mathbf{L}^{2}, \mathbf{L}^{3}\right)$ complexes calculated in aqueous solution (C-PCM) by using the B3LYP model indicate that the $t w$ form is the most stable one along the whole lanthanide series for the complexes of $\mathbf{L}^{3}$, while for those of $\mathbf{L}^{2}$ only the $\mathrm{Gd} \mathrm{d}^{\mathrm{II}}$ complex is more stable in the $t f$ conformation by $c a .0 .5 \mathrm{kcal} \mathrm{mol}^{-1}$. ${ }^{1} \mathrm{H}$ NMR studies of the $\mathrm{Eu}^{\mathrm{III}}$ complex of $\mathbf{L}^{3}$ show the initial formation of the $t f$ complex in aqueous solution, which slowly converts to the thermodynamically stable $t w$ form. The structures calculated for the $\mathrm{Nd}^{\mathrm{III}}$ complexes are in reasonably good agreement with the experimental solution structures, as demonstrated by $\mathrm{Nd}^{\mathrm{III}}$-induced relaxation rate enhancement effects in the ${ }^{1} \mathrm{H}$ NMR spectra.

\section{Introduction}

Coordination chemistry of lanthanide complexes in aqueous solution has been the subject of intense research efforts over the past ten years. ${ }^{1}$ In particular, lanthanide complexes with poly(aminocarboxylate) ligands present considerable interest due to their application as contrast agents for magnetic resonance imaging (MRI), ${ }^{2,3}$ or responsive luminescent lanthanide complexes. ${ }^{4}$ Within the last decade, MRI has become one of the most powerful tools for medical diagnosis. The development of this

${ }^{a}$ Departamento de Química Fundamental, Universidade da Coruña, Alejandro de la Sota 1, 15008 A, Coruña, Spain.E-mail: cplatas@udc.es

${ }^{b}$ Laboratoire de Chimie Inorganique et Bioinorganique, Ecole Polytechnique Fédérale de Lausanne, BCH, CH-1015, Lausanne, Switzerland

'Centre de Biophysique Moléculaire, CNRS, rue Charles-Sadron, 45071 Orléans, Cedex 2, France

$\dagger$ Electronic supplementary information (ESI) available: Optimized Cartesian coordinates $(\AA)$ of the $\left[\mathrm{Ln}(\mathrm{L})\left(\mathrm{H}_{2} \mathrm{O}\right)\right]^{3-} \cdot 19 \mathrm{H}_{2} \mathrm{O}(\mathrm{Ln}=\mathrm{La}, \mathrm{Nd}, \mathrm{Gd}$, Ho or $\mathbf{L u}$; $\mathbf{L}=\mathbf{L}^{2}$ or $\left.\mathbf{L}^{3}\right)$ and $[\mathrm{Lu}(\mathrm{L})]^{3-} \cdot 20 \mathrm{H}_{2} \mathrm{O}\left(\mathbf{L}=\mathbf{L}^{2}\right.$ or $\left.\mathbf{L}^{3}\right)$ systems; hydrogen bonding data for $\left[\mathrm{Gd}(\mathrm{L})\left(\mathrm{H}_{2} \mathrm{O}\right)\right]^{3-} \cdot 19 \mathrm{H}_{2} \mathrm{O}$ and $[\mathrm{Lu}(\mathrm{L})]^{3-} \cdot 20 \mathrm{H}_{2} \mathrm{O}$ $\left(\mathrm{L}=\mathbf{L}^{2}\right.$ or $\left.\mathbf{L}^{3}\right)$ systems; Fig. S1: ${ }^{1} \mathrm{H}$ NMR spectrum of the $\mathrm{Eu}^{\mathrm{III}}$ complex of $\mathbf{L}^{2}$. See DOI: $10.1039 / \mathrm{b} 611544 \mathrm{f}$ technique is related to the successful use of paramagnetic agents, mainly $\mathrm{Gd}^{\mathrm{III}}$ complexes, which enhance the intrinsic contrast of the magnetic resonance images by preferentially influencing the relaxation efficiency of the water proton nuclei in the target tissue. These complexes contain at least one $\mathrm{Gd}^{\mathrm{III}}$-bound water molecule that rapidly exchanges with the bulk water of the body, which imparts an efficient mechanism for the longitudinal and transverse relaxation $\left(T_{1}\right.$ and $\left.T_{2}\right)$ enhancement of water protons. Contrast agents must be stable enough to avoid the in vivo release of toxic free $\mathrm{Gd}^{\mathrm{III}}$. The ligands used must also show a good selectivity for $\mathrm{Gd}^{\mathrm{III}}$ over other metal ions present in body fluids such as the most abundant $\mathrm{Zn}^{\mathrm{II}}$.

In a recent work, ${ }^{5}$ we reported a new receptor containing pyridine units and carboxylate pendants $\left(\mathrm{H}_{4} \mathbf{L}^{1}\right.$, Scheme 1$)$, which forms relatively stable complexes with $\mathrm{Ln}^{\mathrm{III}}$ ions in aqueous solution. ${ }^{6}$ In these complexes, the $\mathrm{Ln}^{\mathrm{III}}$ ion is nine-coordinate, where a water molecule completes the metal ion coordination sphere. This induces a relaxivity in solutions of the complex at the imaging fields comparable to those reported for standard contrast agents such as $\left[\mathrm{Gd}(\mathrm{DOTA})\left(\mathrm{H}_{2} \mathrm{O}\right)\right]^{-}\left(\right.$DOTA $^{4-}=1,4,7,10$-tetraazacyclododecane-1,4,7,10-tetraacetate) and $\left[\mathrm{Gd}(\mathrm{DTPA})\left(\mathrm{H}_{2} \mathrm{O}\right)\right]^{2-}$ 

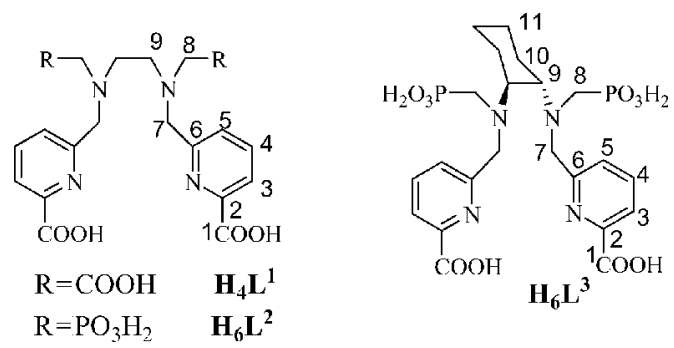

Scheme 1

$\left(\mathrm{DTPA}^{5-}=\right.$ diethylenetriamine- $N, N, N^{\prime}, N^{\prime \prime}, N^{\prime \prime}$-pentaacetate). In previous papers, we have reported two new ligands $\left(\mathrm{H}_{6} \mathbf{L}^{2}\right.$ and $\mathrm{H}_{6} \mathbf{L}^{3}$, Scheme 1) designed for stable complexation of lanthanide ions. ${ }^{7,8}$ The corresponding $\mathrm{Gd}^{\mathrm{III}}$ complexes present an extremely high water exchange rate of the inner sphere water molecule, an important parameter to be optimized for the design of new, more effective, MRI contrast agents. In the present work we report an experimental and theoretical study of the complexation properties of ligands $\mathrm{H}_{6} \mathbf{L}^{2}$ and $\mathrm{H}_{6} \mathbf{L}^{3}$ towards lanthanide and some divalent ions. Ligand $\mathrm{H}_{6} \mathbf{L}^{2}$ maintains the same basic structure as $\mathrm{H}_{4} \mathbf{L}^{\mathbf{1}}$, but the acetate pendants have been replaced by phosphonic acid pendant arms, while ligand $\mathrm{H}_{6} \mathbf{L}^{3}$ contains the same structural backbone as $\mathrm{H}_{6} \mathbf{L}^{2}$ with the ethyl bridge being substituted by a more rigid cyclohexyl moiety. This structural modification has been shown to have an important effect on the water exchange rate of the inner sphere water molecule. ${ }^{8}$ In this work, the corresponding lanthanide complexes were characterized by ${ }^{1} \mathrm{H}$ and ${ }^{13} \mathrm{C}$ NMR techniques in $\mathrm{D}_{2} \mathrm{O}$ solution. Thermodynamic stability constants of the $\mathrm{Gd}^{\mathrm{III}}$ complexes of these ligands have been determined by $\mathrm{pH}$ potentiometry. Stability studies on the complexes of these ligands with some endogenously available metal ions, such as $\mathrm{Cu}^{\mathrm{II}}$ and $\mathrm{Zn}^{\mathrm{II}}$ are also reported. In addition, the complexes were characterized by $a b$ initio calculations carried out at the HF level. These calculations were performed on molecular clusters with formula $\left[\mathrm{Ln}(\mathrm{L})\left(\mathrm{H}_{2} \mathrm{O}\right)\right]^{3-} \cdot 19 \mathrm{H}_{2} \mathrm{O}$ and $[\mathrm{Ln}(\mathrm{L})]^{3-} \cdot 20 \mathrm{H}_{2} \mathrm{O}\left(\mathrm{L}=\mathbf{L}^{2}, \mathbf{L}^{3}\right)$. Calculations on molecular clusters have the advantage of providing useful direct information about the second sphere solvation shell, which has been shown to enhance the relaxivity of $\mathrm{Gd}^{\mathrm{III}}$ chelates bearing phosphonate groups.9,10 The structures established by these calculations were compared with the structural information obtained in solution from paramagnetic NMR measurements $\left(\mathrm{Nd}^{\mathrm{III}}\right.$-induced relaxation rate enhancement effects).

\section{Experimental}

Ligands $\mathrm{H}_{6} \mathbf{L}^{2}$ and $\mathrm{H}_{6} \mathbf{L}^{3}$ were prepared as described previously. ${ }^{8}$ The nitrate salts, $\mathrm{Ln}\left(\mathrm{NO}_{3}\right)_{3} \cdot n \mathrm{H}_{2} \mathrm{O}$, were from Alfa Laboratories, and were used without further purification. $\mathrm{D}_{2} \mathrm{O}$ for NMR studies was obtained from Merck $(99.9 \%$ D).

\section{NMR measurements}

${ }^{1} \mathrm{H},{ }^{13} \mathrm{C}$ and ${ }^{31} \mathrm{P}$ NMR spectra were run on Bruker AC200 F or Bruker Avance 300 spectrometers. Chemical shifts are reported in $\delta$ values. For measurements in $\mathrm{D}_{2} \mathrm{O}$, tert-butyl alcohol was used as an internal standard with the methyl signal calibrated at $\delta=1.2\left({ }^{1} \mathrm{H}\right)$ and $31.2 \mathrm{ppm}\left({ }^{13} \mathrm{C}\right)$. Spectral assignments were based in part on two-dimensional COSY, HMQC and HMBC experiments. Longitudinal ${ }^{1} \mathrm{H}$ relaxation times $T_{1}$ were measured by the inversion-recovery pulse sequence. ${ }^{11}$ Samples of the $\mathrm{Ln}^{\text {III }}$ complexes for NMR measurements were prepared by dissolving equimolar amounts of the ligand and hydrated $\mathrm{Ln}\left(\mathrm{NO}_{3}\right)_{3}$ in $\mathrm{D}_{2} \mathrm{O}$, followed by adjustment of the $\mathrm{pD}$ with $\mathrm{ND}_{4} \mathrm{OD}$ and $\mathrm{DCl}$ (Aldrich) solutions in $\mathrm{D}_{2} \mathrm{O}$. The $\mathrm{pH}$ of the solutions was measured at room temperature with a calibrated microcombination probe purchased from Aldrich Chemical Co. The $\mathrm{pH}$ values were corrected for the deuterium isotope effect using the relationship $\mathrm{pH}=\mathrm{pD}-0.4 .^{12}$

\section{Potentiometry}

The stock solution of $\mathrm{GdCl}_{3}$ was made by dissolving $\mathrm{Gd}_{2} \mathrm{O}_{3}$ in a slight excess of concentrated $\mathrm{HCl}$ in double distilled water. The excess of aqueous $\mathrm{HCl}$ solution was removed by evaporation. Stock solutions of $\mathrm{Zn}^{\mathrm{II}}$ and $\mathrm{Cu}^{\mathrm{II}}$ were prepared from $\mathrm{ZnCl}_{2}$ and $\mathrm{CuSO}_{4}$ salts in double distilled water. The concentration of the solutions was determined by complexometric titration with a standardized $\mathrm{Na}_{2} \mathrm{H}_{2}$ EDTA solution $\left(\mathrm{H}_{4}\right.$ edta $=$ ethylenediaminetetraacetic acid $)$ using xylenol orange as indicator $\left(\mathrm{Zn}^{\mathrm{II}}, \mathrm{Gd}^{\mathrm{III}}\right)$ or by gravimetry $\left(\mathrm{Cu}^{\mathrm{II}}\right)$. Ligand stock solutions were prepared in double distilled water using $\mathrm{KOH}$ to increase the $\mathrm{pH}$ up to 4 in order to avoid precipitation. The exact ligand concentrations were determined by adding excess of $\mathrm{GdCl}_{3}$ to the ligand solution and titrating back the metal excess with standardized $\mathrm{Na}_{2} \mathrm{H}_{2}$ EDTA.

Ligand protonation constants and stability constants with $\mathrm{Zn}^{\mathrm{II}}$, $\mathrm{Cu}^{\mathrm{II}}$ and $\mathrm{Gd}^{\mathrm{III}}$ were determined by $\mathrm{pH}$-potentiometric titration at $25{ }^{\circ} \mathrm{C}$ in $0.1 \mathrm{M} \mathrm{KCl}$. The samples $(2$ or $3 \mathrm{ml})$ were stirred while a constant $\mathrm{N}_{2}$ flow was bubbled through the solutions. The titrations were carried out adding standardized $\mathrm{KOH}$ solution with a Methrom Dosimat 665 automatic burette. A combined glass electrode (C14/02-SC, reference electrode $\mathrm{Ag} / \mathrm{AgCl}$ in $3 \mathrm{M}$ $\mathrm{KCl}$, Moeller Scientific Glass Instruments, Switzerland) and a Metrohm $692 \mathrm{pH} /$ ion-meter were used to measure $\mathrm{pH}$. The $\mathrm{H}^{+}$ concentration was obtained from the measured $\mathrm{pH}$ values using the correction method proposed by Irving et al. ${ }^{13}$ The protonation and stability constants were calculated from parallel titrations with the program PSEQUAD. ${ }^{14}$ The errors given correspond to one standard deviation.

\section{Computational methods}

Full geometry optimizations of the $\left[\mathrm{Ln}(\mathrm{L})\left(\mathrm{H}_{2} \mathrm{O}\right)\right]^{3-} \cdot 19 \mathrm{H}_{2} \mathrm{O}(\mathrm{Ln}=$ $\mathrm{La}, \mathrm{Nd}, \mathrm{Eu}, \mathrm{Gd}, \mathrm{Ho}$ or $\mathrm{Lu})$ and $[\mathrm{Lu}(\mathrm{L})]^{3-} \cdot 20 \mathrm{H}_{2} \mathrm{O}(\mathrm{Ln}=\mathrm{Lu})$ systems were performed in vacuo at the RHF level $\left(\mathrm{L}=\mathbf{L}^{2}\right.$ or $\left.\mathbf{L}^{3}\right)$. For these calculations the effective core potential (ECP) of Dolg et al. ${ }^{15}$ and the related [5s $\left.4 \mathrm{p} 3 \mathrm{~d}\right]-\mathrm{GTO}$ valence basis set were used for the lanthanides, while the $3-21 \mathrm{G}^{*}$ basis set was used for the ligand atoms. The stationary points found on the potential energy surfaces as a result of the geometry optimizations have been tested to represent energy minima rather than saddle points via frequency analysis.

The relative free energies of the twist-wrap (tw) and twist-fold $(t f)$ conformations of $\left[\mathrm{Ln}(\mathrm{L})\left(\mathrm{H}_{2} \mathrm{O}\right)\right]^{3-}$ complexes were calculated in aqueous solution at the DFT (B3LYP functional) ${ }^{16}$ level, by using the $6-311 \mathrm{G}^{* *}$ basis set for the ligand atoms. In these calculations second-sphere water molecules were excluded, and solvent effects were included by using the polarizable continuum model (PCM). In particular, we used the C-PCM variant ${ }^{17}$ that, 
employing conductor rather than dielectric boundary conditions, allows a more robust implementation. The solute cavity is built as an envelope of spheres centered on atoms or atomic groups with appropriate radii. Each sphere is subdivided in 60 initial tesserae in pentakisdodecahedral patterns. For the lanthanides the previously parametrized radius was used. ${ }^{18}$ Final free energies include both electrostatic and non-electrostatic contributions.

The NMR shielding tensors $\left(\mathrm{GIAO}^{19}\right.$ method) of the $\left[\mathrm{La}(\mathrm{L})\left(\mathrm{H}_{2} \mathrm{O}\right)\right]^{3-}\left(\mathrm{L}=\mathbf{L}^{2}\right.$ or $\left.\mathbf{L}^{3}\right)$ systems were calculated in aqueous solution at the B3LYP functional level by using the ECP of Stevens et $a .^{20,21}$ and the $6-311 \mathrm{G}^{* *}$ basis set for the ligand atoms. For chemical shift calculation purposes, NMR shielding tensors of tetramethylsilane (TMS) were calculated at the same computational level. All HF and DFT calculations were performed by using the Gaussian 98 (Revision A.11.3) ${ }^{22}$ and Gaussian 03 (Revision C.1) program packages. ${ }^{23}$

\section{Results and discussion}

\section{Ligand protonation constants and stability constants of the metal complexes}

The protonation constants of ligands $\mathbf{L}^{2}$ and $\mathbf{L}^{3}$ as well as the stability constants of their metal complexes formed with different metals $\left(\mathrm{Gd}^{\mathrm{III}}, \mathrm{Zn}^{\mathrm{II}}\right.$ and $\left.\mathrm{Cu}^{\mathrm{II}}\right)$ were determined by potentiometric titration; the constants and standard deviations are given in Table 1. Table 1 also lists the protonation constants of $\mathbf{L}^{1}$ and the stability constant of its $\mathrm{Gd}^{\mathrm{III}}$ complex reported by Mazzanti et $a l^{6}$ The ligand protonation constants are defined as in eqn (1), and the stability constants of the metal chelates and the protonation constants of the complexes are expressed in eqn (2) and (3), respectively.

$$
\begin{gathered}
K_{i}=\left[\mathrm{H}_{\mathrm{i}} \mathrm{L}\right] /\left[\mathrm{H}_{i-1} \mathrm{~L}\right]\left[\mathrm{H}^{+}\right] \\
K_{\mathrm{ML}}=[\mathrm{ML}] /[\mathrm{M}][\mathrm{L}]
\end{gathered}
$$

Table 1 Protonation constants of the ligands and stability constants of their metal complexes $\left(25^{\circ} \mathrm{C} ; I=0.1 \mathrm{M} \mathrm{KCl}\right)$

\begin{tabular}{lccr}
\hline & $\mathbf{L}^{1}{ }^{a}$ & \multicolumn{1}{l}{$\mathbf{L}^{2}$} & \multicolumn{1}{l}{$\mathbf{L}^{3}$} \\
\hline $\log K_{1}$ & 8.5 & $10.21(2)$ & $10.03(3)$ \\
$\log K_{2}$ & 5.2 & $8.84(3)$ & $9.69(2)$ \\
$\log K_{3}$ & 3.5 & $6.59(4)$ & $5.88(4)$ \\
$\log K_{4}$ & 2.9 & $5.16(4)$ & $5.08(4)$ \\
$\log K_{5}$ & & $3.94(4)$ & $4.39(4)$ \\
$\log K_{6}$ & & $1.4(1)$ & $3.20(4)$ \\
& & & \\
$\log K_{\mathrm{GdL}}$ & 15.1 & $b$ & $17.62(8)$ \\
$\log K_{\mathrm{GdHL}}$ & & $6.01(3)$ & $6.61(7)$ \\
$\log K_{\mathrm{GdH}_{2} \mathrm{~L}}$ & & $5.00(5)$ & $5.41(8)$ \\
$\log K_{\mathrm{GdH}_{3} \mathrm{~L}}$ & & $b$ & $4.86(4)$ \\
$\log K_{\mathrm{ZnL}}$ & & $6.94(7)$ & $6.84(1)$ \\
$\log K_{\mathrm{ZnHL}}$ & & $6.60(4)$ & $6.01(1)$ \\
$\log K_{\mathrm{ZnH}_{2} \mathrm{~L}}$ & & & $5.13(2)$ \\
$\log K_{\mathrm{ZnH}_{3} \mathrm{~L}}$ & & $b$ & $18.17(8)$ \\
$\log K_{\mathrm{CuL}}$ & & $7.08(7)$ & $7.7(1)$ \\
$\log K_{\mathrm{CuHL}}$ & & $6.77(5)$ & $7.03(5)$ \\
$\log K_{\mathrm{CuH}_{2} \mathrm{~L}}$ & & &
\end{tabular}

${ }^{a}$ From ref. $6 .{ }^{b}$ The complex is too stable to determine the stability constant by direct titration.

$$
K_{\mathrm{MH}_{i} \mathrm{~L}}=\left[\mathrm{MH}_{i} \mathrm{~L}\right] /\left[\mathrm{MH}_{i-1} \mathrm{~L}\right]\left[\mathrm{H}^{+}\right] ; i=1,2,3
$$

In comparison with $\mathbf{L}^{1}$, the $\mathbf{L}^{2}$ and $\mathbf{L}^{3}$ ligands have higher protonation constants for the first and second protonation steps, which occur on the amine nitrogen atoms. ${ }^{6}$ Thus, replacement of the acetate pendants of $\mathbf{L}^{1}$ by methylphosphonate groups leads to an important increase in the basicity of the two amine nitrogen atoms. The first protonation constant of $\mathbf{L}^{2}$ and $\mathbf{L}^{3}$ is very similar to that reported for ethylenediaminediphosphonic acid (EDDP, $\log K_{1}=10.29$ ), while the second protonation constant is higher in $\mathbf{L}^{2}$ and $\mathbf{L}^{3}$ than in EDDP $\left(\log K_{2}=7.85\right) .{ }^{24}$ The third and fourth protonation steps of $\mathbf{L}^{2}$ and $\mathbf{L}^{3}$ correspond to partial protonation of the phosphonate groups, which occur at slightly higher $\mathrm{pH}$ than in EDDP $\left(\log K_{3}=5.40, \log K_{4}=4.35\right){ }^{24}$ The last two protonation steps probably correspond to the protonation of the pyridylcarboxylate groups. ${ }^{6}$

Potentiometric titrations of the $\mathbf{L}^{2}$ and $\mathbf{L}^{3}$ ligands have been carried out in the presence of equimolar $\mathrm{Gd}^{\mathrm{III}}$ in order to determine the stability constants of the metal complexes. The analysis of the titration curve for $\mathrm{Gd}^{2}$ shows that already at the beginning of the titration ( $\mathrm{pH} \sim 2$ ), there is no free $\mathrm{Gd}^{\mathrm{III}}$, all metal being in the form of the diprotonated complex. Therefore, we could not calculate the stability constant for this complex; only an estimation of $\log K_{\mathrm{GdL}^{2}}>20$ can be made. Both mono- and diprotonated forms of the $\mathrm{Gd}^{\mathrm{III}}$ complex have been detected over the $\mathrm{pH}$ range studied. These protonation steps are expected to occur on the phosphonate groups. Partial protonation of phosphonate groups in solution has been observed previously for $\mathrm{Ln}^{\mathrm{III}}$ complexes with both cyclic ${ }^{25,26}$ and acyclic ${ }^{9}$ ligands. The species distribution diagram for the $\mathrm{GdL}^{2}$ system (Fig. 1) shows the presence of monoprotonated complex in solution at $\mathrm{pH}<8$, while the second protonation of the complex occurs at $\mathrm{pH}<7$.

The species distribution curves obtained for $\mathrm{Gd}^{3}$ (Fig. 1) indicate dissociation of the complex at low $\mathrm{pH}$, which allowed us to determine the stability constant for this complex. This result points to a lower stability of the $\mathrm{Gd}^{\mathrm{III}}$ complex of $\mathbf{L}^{3}$ in comparison to that of $\mathbf{L}^{2}$. Thus, increasing the rigidity of the ligand lowers the stability of the corresponding $\mathrm{Gd}^{\mathrm{III}}$ complex. The stability constant obtained $\left(\log K_{\mathrm{GdL}^{3}}=17.62\right.$, Table 1$)$ is approximately 2 $\log$ units higher than that of $\mathrm{Gd}^{1}{ }^{1},{ }^{6}$ and similar to that reported for GdEDTA $\left(\log K_{\mathrm{GdL}}=17.37\right){ }^{27}$

$\mathrm{Cu}^{\text {II }}$ and $\mathrm{Zn}^{\text {II }}$ complexes are found to be highly stable with both $\mathbf{L}^{2}$ and $\mathbf{L}^{3}$; a quantitative assessment by direct potentiometry was only possible for $\mathrm{CuL}^{3}$ (Table 1). As for the $\mathrm{Gd}^{\mathrm{III}}$ analogues, protonated complexes are present in all systems in an extended $\mathrm{pH}$ range.

Non-toxicity is primordial for in vivo application of $\mathrm{Gd}^{\mathrm{III}}$ (or other metal) complexes as MRI contrast agents. It is evident that competitive equilibria cannot solely explain the in vivo behavior of $\mathrm{Gd}^{\mathrm{III}}$ complexes. The excretion of low molecular weight $\mathrm{Gd}^{\mathrm{III}}$ chelates from the body is very rapid $\left(t_{1 / 2}=1.6 \mathrm{~h}\right.$ for $\left.\operatorname{Gd}(\mathrm{DTPA})^{2-}\right)$, whereas the dissociation and transmetallation of the $\mathrm{Gd}^{\mathrm{III}}$ complexes can be relatively slow. Therefore, the system is far from equilibrium, and kinetic factors must be considered ${ }^{28-30}$ A detailed kinetic investigation was beyond the scope of this study. However, we know that the present complexes protonate readily and the protonated species are expected to have modest kinetic stability with respect to proton mediated decomplexation, as it 

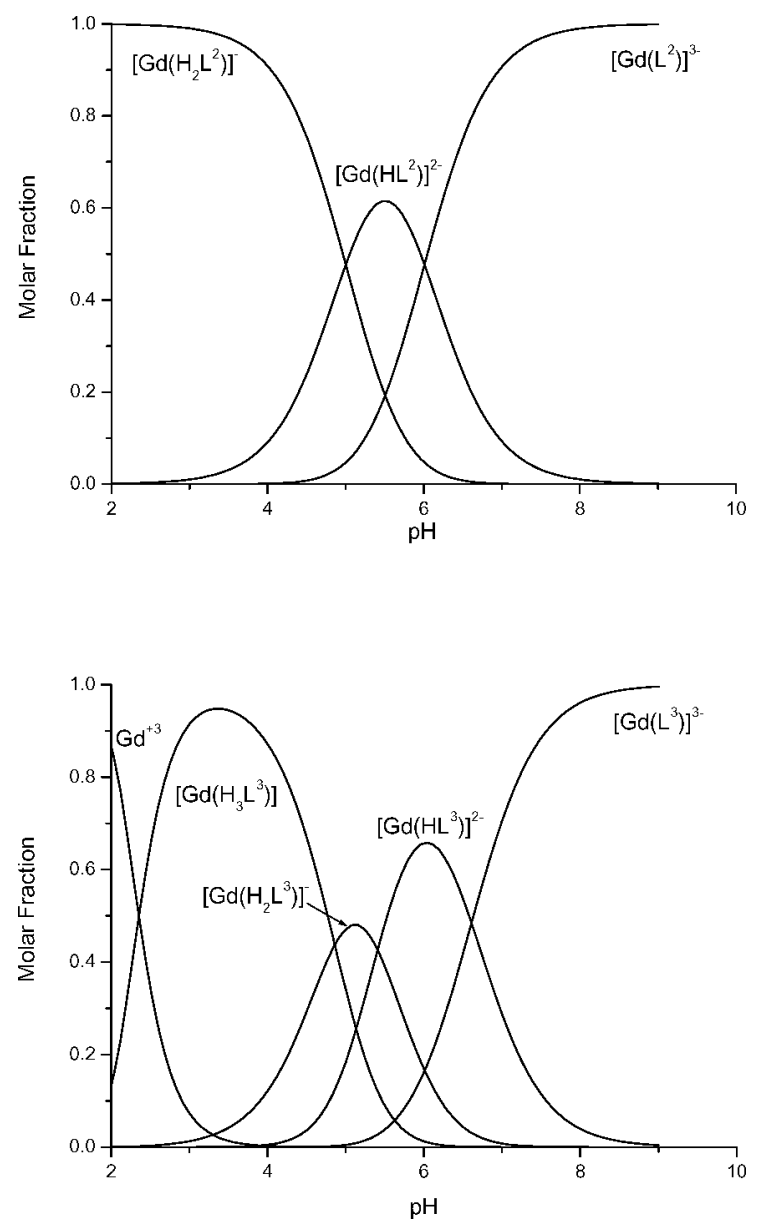

Fig. 1 Species distribution of the $\mathrm{Gd} \mathbf{L}^{2}$ (top) and $\mathrm{Gd} \mathbf{L}^{3}$ (bottom) systems, $1: 1 \mathrm{Gd}^{\mathrm{III}}: \mathrm{L} ;\left[\mathrm{Gd}^{\mathrm{III}}\right]=1 \mathrm{mM}, \mu=0.1 \mathrm{M}(\mathrm{KCl}), T=25^{\circ} \mathrm{C}$.

was recently shown for DTPA analogues with a phosphonic acid pendant arm. ${ }^{31}$

\section{NMR spectra}

The ${ }^{1} \mathrm{H},{ }^{31} \mathrm{P}$ and ${ }^{13} \mathrm{C}$ NMR spectra of the $\mathrm{La}^{\mathrm{III}}$ complexes of $\mathbf{L}^{2}$ and $\mathbf{L}^{3}$ were obtained in $\mathrm{D}_{2} \mathrm{O}$ solution at $\mathrm{pH}=7$.6. At this $\mathrm{pH}$ the major species in solution is expected to be the fully deprotonated form $\left[\mathrm{Ln}(\mathrm{L})\left(\mathrm{H}_{2} \mathrm{O}\right)_{n}\right]^{3-}$, as demonstrated by our potentiometric measurements (see above). The proton spectra (Fig. 2) consist of $9\left(\mathbf{L}^{2}\right)$ and $12\left(\mathbf{L}^{3}\right)$ signals corresponding to the different proton magnetic environments of the ligand molecule (see Scheme 1 for labelling scheme). This points to an effective $C_{2}$ symmetry of the complexes in solution that is confirmed by the ${ }^{13} \mathrm{C}$ spectra, which show nine NMR peaks for the 18 carbon nuclei of $\mathbf{L}^{2}$ and 11 signals for the 22 carbon nuclei of $\mathbf{L}^{3}$ in the corresponding complexes. The ${ }^{13} \mathrm{C}$ NMR spectra show two doublets for the phosphonate carbon atoms $\mathrm{C} 8\left({ }^{2} J_{\mathrm{C8}-\mathrm{P}} \sim 140 \mathrm{~Hz}\right)$ and $\mathrm{C} 7\left({ }^{3} J_{\mathrm{C} 7 \mathrm{P}} \sim 16\right.$ $\mathrm{Hz}$ ). Similar coupling constants have been observed for other $\mathrm{La}^{\mathrm{III}}$ complexes with ligands containing phosphonate groups. ${ }^{32} \mathrm{The}^{31} \mathrm{P}$ NMR spectra recorded at $298 \mathrm{~K}$ show a single peak at $c a .17 \mathrm{ppm}$, again in agreement with an effective $C_{2}$ symmetry of the complexes in solution. The assignments of the proton signals (Table 2) were aided with standard 2D homonuclear COSY experiments, which gave strong cross-peaks between the geminal $\mathrm{CH}_{2}$-protons
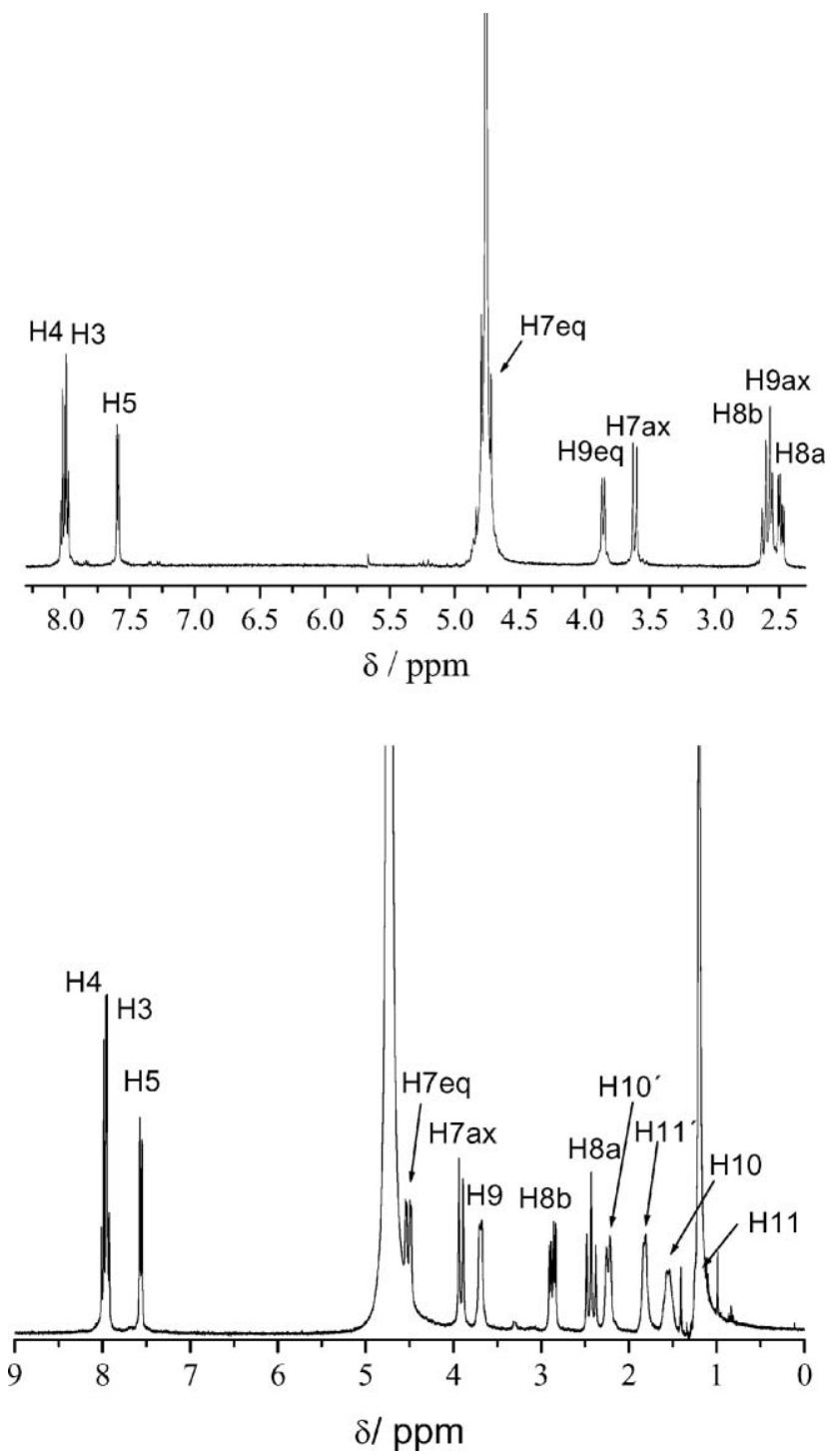

Fig. $2{ }^{1} \mathrm{H}$ NMR spectra of the $\mathbf{L a}{ }^{\mathrm{III}}$ complexes of $\mathbf{L}^{2}$ (top) and $\mathbf{L}^{3}$ (bottom) recorded in $\mathrm{D}_{2} \mathrm{O}$ solutions $(30 \mathrm{mM}, \mathrm{pH}=7.6,298 \mathrm{~K})$.

and between ortho-coupled pyridyl protons. A full assignment of the ${ }^{1} \mathrm{H}$ and ${ }^{13} \mathrm{C}$ NMR spectra was achieved with the aid of 2D heteronuclear HMQC and HMBC experiments. The HMBC spectra show a signal relating $\mathrm{H} 5$ with one of the aliphatic carbon nuclei of the ligand backbone, which was therefore assigned to $\mathrm{C} 7$. The signals corresponding to protons $\mathrm{H} 8$ could be easily identified due to the presence of important ${ }^{2} J_{\mathrm{H}-\mathrm{P}}$ couplings ( $c a .6 \mathrm{~Hz}$, Table 2$)$. Protons $\mathrm{H} 7$ and $\mathrm{H} 8$ yield two multiplets, consisting of the $\mathrm{AB}$ part of a $\mathrm{ABX}$ spectrum ( $\mathrm{X}$ is the ${ }^{31} \mathrm{P}$ nucleus). Although the specific $\mathrm{CH}_{2}$ proton assignments $\mathrm{H} 9 \mathrm{ax} / \mathrm{H} 9 \mathrm{eq}, \mathrm{H} 8 \mathrm{a} / \mathrm{H} 8 \mathrm{~b}$ and $\mathrm{H} 7 \mathrm{ax} / \mathrm{H} 7 \mathrm{eq}$, were not possible on the basis of the 2D NMR spectra, they were carried out using the stereochemically dependent proton shift effects, resulting from the polarization of the $\mathrm{C}-\mathrm{H}$ bonds by the electric field effect caused by the cation charge. ${ }^{33}$ This results in a deshielding effect of the H9eq, H7eq and $\mathrm{H} 8 \mathrm{~b}$ protons, which are pointing away from the $\mathrm{La}^{\mathrm{III}}$ ion.

The ${ }^{1} \mathrm{H}$ NMR spectra of the diamagnetic $\mathrm{Lu}^{\text {III }}$ complexes recorded at $298 \mathrm{~K}$ are more complex than those of the corresponding La $\mathrm{La}^{\mathrm{III}}$ analogues. Although this complexity prevented 
Table $2{ }^{1} \mathrm{H}$ shifts (ppm) for the $\mathbf{L n}{ }^{\text {III }}$ complexes of $\mathbf{L}^{2}$ and $\mathbf{L}^{3}$ in $30 \mathrm{mM} \mathrm{D} \mathrm{D}_{2} \mathrm{O}$ solutions at $\mathrm{pH} 7.6$

\begin{tabular}{|c|c|c|c|c|c|c|c|c|}
\hline & \multicolumn{2}{|c|}{$\mathrm{La}^{I I I a}$} & \multicolumn{2}{|l|}{$\mathrm{Ce}^{\mathrm{III}}$} & \multicolumn{2}{|l|}{$\mathrm{Nd}^{\mathrm{III}}$} & \multicolumn{2}{|l|}{$\mathrm{Eu}^{\mathrm{III}}$} \\
\hline & $\mathbf{L}^{2 b}$ & $\mathbf{L}^{3 c}$ & $\mathbf{L}^{2}$ & $\mathbf{L}^{3}$ & $\mathbf{L}^{2}$ & $\mathbf{L}^{3}$ & $\mathbf{L}^{2}$ & $\mathbf{L}^{3}$ \\
\hline $\mathrm{H} 3$ & 7.96 & 7.96 & 10.72 & 10.49 & 9.61 & 10.24 & 6.44 & 6.15 \\
\hline $\mathrm{H} 4$ & 7.99 & 7.96 & 9.94 & 9.70 & 9.42 & 9.82 & 6.60 & 6.50 \\
\hline H5 & 7.57 & 7.56 & 8.75 & 8.40 & 8.67 & 9.00 & 6.44 & 6.44 \\
\hline H7ax & 3.61 & 3.91 & 7.08 & 8.50 & 2.51 & 2.97 & 6.91 & 9.63 \\
\hline $\mathrm{H} 7 \mathrm{eq}$ & 4.76 & 4.51 & 1.46 & 1.37 & 5.05 & 1.20 & -1.22 & 2.36 \\
\hline $\mathrm{H} 8 \mathrm{a}^{\mathrm{T}}$ & 2.49 & 2.43 & -12.70 & -2.27 & -5.11 & -8.35 & 16.13 & 10.95 \\
\hline $\mathrm{H} 8 \mathrm{~b}$ & 2.63 & 2.87 & -5.19 & -6.75 & 1.68 & -0.66 & 3.33 & 1.29 \\
\hline H9ax & 2.57 & 3.69 & -3.51 & 1.20 & -4.26 & -4.98 & 11.63 & 15.77 \\
\hline H9eq & 3.86 & & -2.66 & & 1.30 & & -0.11 & \\
\hline $\mathrm{H} 10$ & & 1.55 & & 0.44 & & -2.58 & & 7.86 \\
\hline $\mathrm{H} 10^{\prime}$ & & 2.24 & & -0.52 & & -1.95 & & 8.04 \\
\hline H11 & & 1.2 & & -1.40 & & -1.18 & & 4.70 \\
\hline H11 & & 1.82 & & -1.65 & & 0.41 & & 3.55 \\
\hline
\end{tabular}

${ }^{a}$ Assignment supported by 2D H,H COSY, HMQC, and HMBC experiments at $298 \mathrm{~K} .{ }^{b}{ }^{2} J_{9 \mathrm{ax}, 9 \mathrm{eq}}=9.4 \mathrm{~Hz} ;{ }^{2} J_{9 \mathrm{eq}, 9 \mathrm{ax}}=10.6 \mathrm{~Hz} ;{ }^{2} J_{7 \mathrm{eq}, 7 \mathrm{ax}}=14.6 \mathrm{~Hz} ;{ }^{2} J_{\text {7ax,7eq }}=$ $14.6 \mathrm{~Hz} ;{ }^{2} J_{8 b, 8 \mathrm{a}}=14.8 \mathrm{~Hz} ;{ }^{2} J_{8 \mathrm{a}, 8 \mathrm{~b}}=14.8 \mathrm{~Hz} ;{ }^{3} J_{5,4}=7.3 \mathrm{~Hz} ;{ }^{3} J_{3,4}=7.3 \mathrm{~Hz} ; \boldsymbol{J}_{\mathrm{Hz}-\mathrm{P}}=5.8 \mathrm{~Hz} .{ }^{c} \boldsymbol{J}_{7 \mathrm{eq}, 7 \mathrm{ax}}=14.4 \mathrm{~Hz} ;{ }^{2} \boldsymbol{J}_{7 \mathrm{ax}, 7 \mathrm{eq}}=14.4 \mathrm{~Hz} ;{ }^{2} \boldsymbol{J}_{8 \mathrm{~b}, 8 \mathrm{a}}=14.9 \mathrm{~Hz} ;{ }^{2} \boldsymbol{J}_{8 \mathrm{a}, 8 \mathrm{~b}}=$ $15.5 \mathrm{~Hz} ;{ }^{3} J_{5,4}=6.4 \mathrm{~Hz} ;{ }^{3} J_{3,4}=6.4 \mathrm{~Hz} ; J_{\mathrm{H} 8-\mathrm{P}}=6.6 \mathrm{~Hz} ; J_{\mathrm{H} 7 \mathrm{P}}=3.9 \mathrm{~Hz}$.

the assignment of the spectra, they suggest the presence of two species in solution with a $C_{1}$ symmetry. These results point to an increasing rigidity of the complexes in aqueous solutions on decreasing the ionic radius of the $\mathrm{Ln}^{\mathrm{III}}$ ion, as previously observed for other $\mathrm{Ln}^{\mathrm{III}}$ complexes. ${ }^{34}$ In the case of the complex of $\mathbf{L}^{2}$ the ${ }^{31} \mathrm{P}$ NMR spectrum recorded at $298 \mathrm{~K}$ indicates the presence of an equilibrium between two species with an effective $C_{1}$ symmetry. It shows a pair of signals of equal intensity at 21.5 and $18.5 \mathrm{ppm}$ and a second pair of less intense signals at 22.4 and $13.7 \mathrm{ppm}$.

${ }^{1} \mathrm{H}$ NMR spectra of the paramagnetic $\mathrm{Ce}^{\mathrm{III}}, \mathrm{Nd}^{\mathrm{III}}$ and $\mathrm{Eu}^{\mathrm{III}}$ complexes of $\mathbf{L}^{2}$ and $\mathbf{L}^{3}$ were obtained in $\mathrm{D}_{2} \mathrm{O}$ solution at $\mathrm{pH}=7.4$, and were assigned by comparison to the spectra of $\mathbf{L}^{1}$ complexes and with the aid of line-width analysis and COSY spectra, which gave cross-peaks between the geminal $\mathrm{CH}_{2}$ protons and between ortho pyridyl protons. The spectra of the $\mathbf{L}^{2}$ complexes show relatively sharp peaks, and they point to an effective $C_{2}$ symmetry of the complexes in solution (Table 2, Fig. S1, ESI $\dagger$ ). The complexes of $\mathbf{L}^{3}$ behave differently in solution: the spectra indicate the formation of two distinct complex species whose concentration changes with time. The spectra acquired immediately after mixing stoichiometric amounts of the ligand and $\mathrm{Ln}^{\text {III }}$ show a single complex species in solution with $C_{1}$ symmetry, which converts slowly to a thermodynamically stable species with an effective $C_{2}$ symmetry. This behavior is illustrated in Fig. 3 with the ${ }^{1} \mathrm{H}$ NMR spectra of the $\mathrm{Eu}^{\mathrm{III}}$ complex of $\mathbf{L}^{3}$ recorded immediately after the preparation of the complex and after heating the solution at $60{ }^{\circ} \mathrm{C}$ for $24 \mathrm{~h}$. Our ab initio calculations discussed below provide two different minimum energy conformations for the $\mathbf{L}^{3}$ complexes: twist-wrap $(t w)$, in which the ligand wraps around the metal ion by twisting the pyridyl units relative to each other, and twist-fold $(t f)$, where the slight twisting of the pyridyl units is accompanied by an overall folding of the two pyridine units towards one of the phosphonate groups. Due to this folding, the $t w$ form shows a molecular geometry that is closer to a $C_{2}$ symmetry than the tf conformation. Thus, we assign the thermodynamically stable form showing $C_{2}$ symmetry to the $t w$ isomer, while the kinetic complex is attributed to the $t f$ conformation. It should be noted that the two conformations of the $\mathrm{Gd}^{\mathrm{III}}$ complex are characterized by identical proton relaxivities.

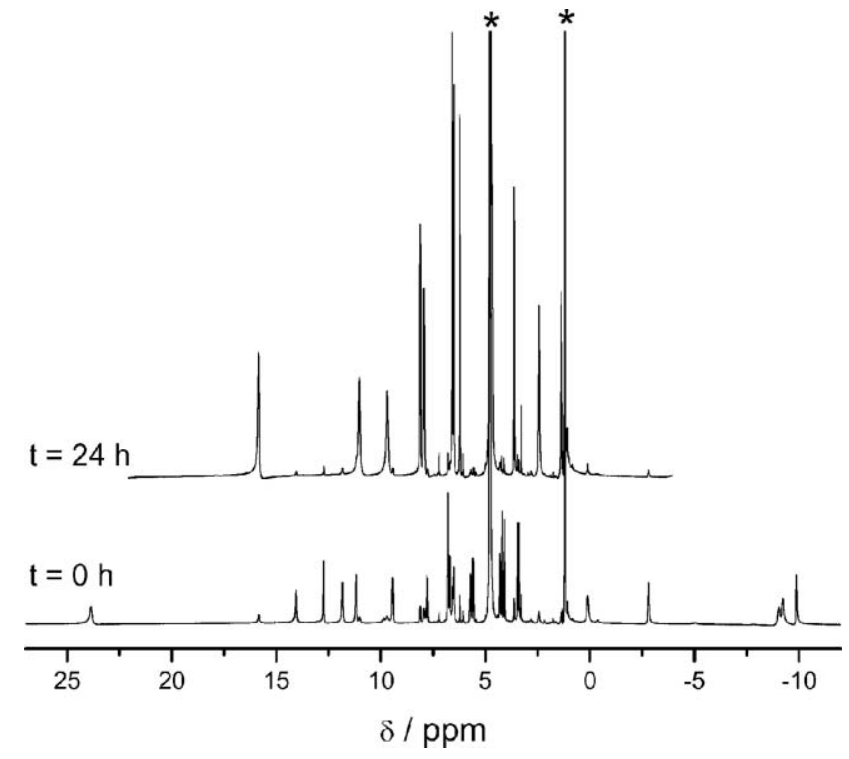

Fig. $3{ }^{1} \mathrm{H}$ NMR spectra of the Eu${ }^{\mathrm{III}}$ complex of $\mathbf{L}^{3}$ recorded in $\mathrm{D}_{2} \mathrm{O}$ solution $(30 \mathrm{mM}, \mathrm{pH}=7.6,298 \mathrm{~K})$ immediately after the preparation of the complex and after heating the solution at $60{ }^{\circ} \mathrm{C}$ for $24 \mathrm{~h}$. HOD and ${ }^{t} \mathrm{BuOH}$ signals are denoted with an asterisk. The assignment of the spectrum recorded at $t=24 \mathrm{~h}$ is given in Table 2 .

\section{Ab initio calculations: molecular geometries}

The $\left[\operatorname{Ln}\left(\mathbf{L}^{2}\right)\left(\mathrm{H}_{2} \mathrm{O}\right)\right]^{3-}$ systems $(\mathrm{Ln}=\mathrm{La}, \mathrm{Nd}, \mathrm{Gd}, \mathrm{Ho}$ or $\mathrm{Lu})$ were investigated by means of ab initio calculations at the HF/3$21 \mathrm{G}^{*}$ level. In the case of $\mathrm{Gd}^{\mathrm{III}}$ complexes, the long electronic relaxation time of the metal ion prevents any observation of NMR spectra, and for this reason their solution structures and properties have to be deduced from the NMR spectra of other lanthanide complexes. Theoretical calculations provide direct information on gadolinium systems as well as on those dynamic processes that are usually too fast to be observed on the NMR time scale, such as the water exchange process. As there is not a good all-electron basis set for lanthanides, the effective core potential (ECP) of Dolg et al. and the related [5s4p3d]-GTO valence basis set was 
applied in these calculations. ${ }^{15}$ This ECP includes $46+4 \mathrm{f}^{n}$ electrons in the core, leaving the outermost 11 electrons to be treated explicitly, and it has been demonstrated to provide reliable results for the lanthanide aqua-ions,$^{18}$ several lanthanide complexes with polyaminocarboxylate ligands $s^{35,36}$ and lanthanide dipicolinates. ${ }^{37}$ Compared to all-electron basis sets, ECPs account to some extent for relativistic effects, which are believed to become important for the elements from the fourth row of the periodic table.

The in vacuo geometry optimization of the $\left[\mathrm{Gd}\left(\mathbf{L}^{2}\right)\left(\mathrm{H}_{2} \mathrm{O}\right)\right]^{3-}$ system provides a minimum energy conformation very similar to that found for $\left[\mathrm{Gd}\left(\mathbf{L}^{1}\right)\left(\mathrm{H}_{2} \mathrm{O}\right)\right]^{-},{ }^{5}$ in which the phosphonate pendant arms are alternatively situated above and below the planes of the pyridyl units. In this structure the distance between the $\mathrm{Gd}^{\mathrm{III}}$ ion and the oxygen atom of the water molecule is large $\left(\mathrm{Gd}-\mathrm{O}_{\mathrm{w}}=\right.$ $2.803 \AA$ ), and this water molecule is hydrogen bonded to one of the phosphonate pendants. Thus, we have tried geometry optimizations of the $\left[\mathrm{Gd}\left(\mathbf{L}^{2}\right)\left(\mathrm{H}_{2} \mathrm{O}\right)\right]^{3-}$ system including the surrounding solvent effects by using the C-PCM model. Unfortunately, because of the optimization convergence difficulty by the C-PCM model ${ }^{38,39}$ these studies were unsuccessful. An alternative to the use of a continuum model of solvation such as C-PCM is to perform cluster calculations that explicitly include a second hydration shell. ${ }^{38,40}$ These calculations have the advantage that minima and transition states can be optimized and characterized in order to study reactions. Moreover, cluster calculations may also provide useful direct information about the second sphere solvation shell, which has been shown to enhance the relaxivity of $\mathrm{Gd}^{\mathrm{III}}$ chelates bearing phosphonate groups. The major disadvantage of cluster calculations is that adding extra solvent molecules to the first solvation sphere increases the computational cost. Moreover, the more atoms are included in the system, the larger the number of degrees of freedom and the higher the number of minimum energy structures. For the $\left[\mathrm{Gd}(\mathrm{L})\left(\mathrm{H}_{2} \mathrm{O}\right)\right]^{3-}$ complexes $\left(\mathbf{L}=\mathbf{L}^{2}, \mathbf{L}^{3}\right)$ we have explicitly included $19 \mathrm{H}_{2} \mathrm{O}$ molecules in the second hydration shell. Our calculations provide two different minimum energy geometries where the ligand adopts different conformations (Fig. 4): twist-wrap $(t w)$, in which the ligand wraps around the metal ion by twisting the pyridyl units relative to each other, and twist-fold $(t f)$, where the slight twisting of the pyridyl units is accompanied by an overall folding of the two pyridine units towards one of the phosphonate groups. The $t f$ conformation shows a smaller $\mathrm{N}_{\mathrm{py}}-$ $\mathrm{Gd}-\mathrm{N}_{\mathrm{py}}$ angle than the $t w$ one $\left(\mathrm{N}_{\mathrm{py}}=\right.$ pyridine nitrogen atom). Both minimum energy structures are true energy minima because the vibrational frequency analyses give no imaginary frequencies. Calculated geometrical parameters (bond distances and angles) of the $\mathrm{Gd}^{\mathrm{III}}$ coordination spheres of these systems are listed in Table 3. The calculated $\mathrm{Gd}-\mathrm{O}_{\mathrm{w}}$ distances $(2.515-2.543 \AA)$ are in excellent agreement with that normally assumed in the analysis of ${ }^{17} \mathrm{O}$ NMR longitudinal relaxation data $(2.50 \AA)$. For the $\mathbf{L}^{3}$ complex, our calculations provide minimum energy conformations with the cyclohexyl unit in chair conformation.

In order to obtain information about the solution structures of this series of $\mathrm{Ln}^{\text {III }}$ complexes, we also performed geometry optimizations of the molecular clusters $\left[\mathrm{Ln}(\mathrm{L})\left(\mathrm{H}_{2} \mathrm{O}\right)\right]^{3-} \cdot 19 \mathrm{H}_{2} \mathrm{O}$ $(\mathrm{Ln}=\mathrm{La}, \mathrm{Nd}, \mathrm{Ho}$ or $\mathrm{Lu})$ at the HF/3-21G* level. Moreover, since the complexes appear to exist in aqueous solution as a mixture of two hydration isomers with $q=0$ and $q=1,{ }^{8}$ we also studied the $[\mathrm{Lu}(\mathrm{L})]^{3-} \cdot 20 \mathrm{H}_{2} \mathrm{O}$ systems. Frequency calculations show that all calculated structures correspond to energy minima.

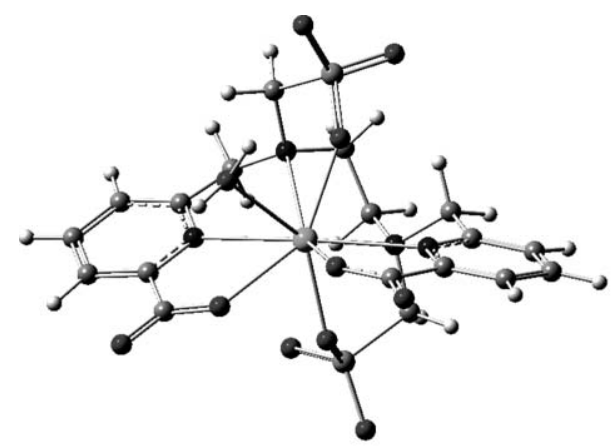

(tw)

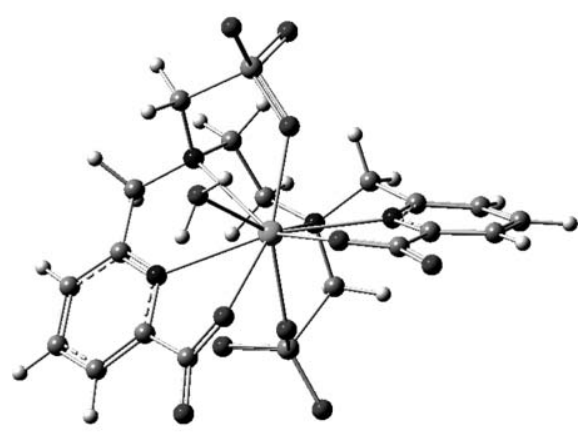

(tf)

Fig. 4 Molecular geometries of the twist-wrap $(t w)$ and twist-fold $(t f)$ isomers of $\left[\mathrm{Gd}\left(\mathbf{L}^{2}\right)\left(\mathrm{H}_{2} \mathrm{O}\right)\right]^{3-}$ complexes obtained from cluster calculations on the $\left[\mathrm{Gd}\left(\mathbf{L}^{2}\right)\left(\mathrm{H}_{2} \mathrm{O}\right)\right]^{3-} \cdot 19 \mathrm{H}_{2} \mathrm{O}$ system. Uncoordinated water molecules have been removed for better visualization.

Optimized Cartesian coordinates obtained for the different $\mathrm{Ln}^{\mathrm{III}}$ systems presented in this work are given in the ESI. $\dagger$ Calculated geometrical parameters (bond distances and angles) of the $\mathrm{Ln}^{\mathrm{III}}$ coordination spheres of these systems are listed in Table 3.

Attempts to model the $[\mathrm{Ln}(\mathrm{L})]^{3-}$ complexes $(\mathrm{Ln}=\mathrm{La}, \mathrm{Nd}, \mathrm{Gd}$ or Ho) were unsuccessful, since a water molecule systematically entered the metal coordination sphere during the optimization process. However, the smaller ionic radius of $\mathrm{Lu}^{\mathrm{III}}$ allowed us to model both the $[\mathrm{Lu}(\mathrm{L})]^{3-}$ and $\left[\mathrm{Lu}(\mathrm{L})\left(\mathrm{H}_{2} \mathrm{O}\right)\right]^{3-}$ complexes in $t w$ conformation. A comparison of the bond distances of the $\mathrm{Lu}^{\text {III }}$ coordination sphere in the $\left[\mathrm{Lu}(\mathrm{L})\left(\mathrm{H}_{2} \mathrm{O}\right)\right]^{3-} \cdot 19 \mathrm{H}_{2} \mathrm{O}$ and $[\mathrm{Lu}(\mathrm{L})]^{3-} \cdot 20 \mathrm{H}_{2} \mathrm{O}$ molecular clusters reveals that the depletion of the coordinated water molecule results in a considerable shortening of the $\mathrm{Lu}^{\mathrm{III}}-\mathrm{L}$ bond distances (Table 3 ).

The relative free energies of the twist-wrap $(t w)$ and twist-fold $(t f)$ conformations of $\left[\mathrm{Ln}(\mathrm{L})\left(\mathrm{H}_{2} \mathrm{O}\right)\right]^{3-}\left(\mathrm{L}=\mathbf{L}^{2}, \mathbf{L}^{3}\right)$ complexes were calculated in aqueous solution by using the B3LYP model and the 6-311 $\mathrm{G}^{* *}$ basis set for the ligand atoms. In these calculations second sphere water molecules were excluded, and solvent effects were included by using the polarizable continuum model (C-PCM). It has been demonstrated that this computational approach provides relative energies of the two isomers of $\left[\mathrm{Ln}(\mathrm{DOTA})\left(\mathrm{H}_{2} \mathrm{O}\right)\right]^{-}$in close agreement to the experimental ones. ${ }^{36}$ Relative free energies were calculated as $\Delta G^{\text {sol }}=G^{\text {sol }}{ }_{(t)}-G^{\text {sol }}{ }_{(t w)}$, and therefore a positive relative energy indicates that the $t w$ conformation is more stable than the $t f$ one. According to our results (Fig. 5), the relative energy of the $t f$ conformation decreases along the first half of 
Table 3 Values of the main geometrical parameters of calculated structures for $\left[\mathrm{Ln}(\mathrm{L})\left(\mathrm{H}_{2} \mathrm{O}\right)\right]^{3-} \cdot 19 \mathrm{H}_{2} \mathrm{O}\left(\mathrm{L}=\mathbf{L}^{2}, \mathbf{L}^{3}\right)$ complexes at the $\mathrm{HF} / 3-21 \mathrm{G}^{*}$ level ${ }^{a}$

\begin{tabular}{|c|c|c|c|c|c|c|}
\hline \multirow[b]{2}{*}{$\mathrm{La}$} & \multicolumn{3}{|l|}{$\mathbf{L}^{2}$} & \multicolumn{3}{|l|}{$\mathbf{L}^{3}$} \\
\hline & $\overline{t w(q=1)}$ & $t f(q=1)$ & $t w(q=0)$ & $\overline{t w(q=1)}$ & $t f(q=1)$ & $t w(q=0)$ \\
\hline $\mathrm{La}-\mathrm{N}_{\mathrm{am}}(1)$ & 3.061 & 2.941 & & 3.071 & 2.904 & \\
\hline $\mathrm{La}-\mathrm{N}_{\mathrm{am}}(2)$ & 2.962 & 2.918 & & 3.075 & 2.958 & \\
\hline $\mathrm{La}-\mathrm{N}_{\mathrm{py}}(2)$ & 2.741 & 2.731 & & 2.722 & 2.730 & \\
\hline $\mathrm{La}-\mathrm{O}_{\mathrm{COO}}(1)$ & 2.513 & 2.500 & & 2.525 & 2.606 & \\
\hline $\mathrm{La}-\mathrm{O}_{\mathrm{COO}}(2)$ & 2.487 & 2.527 & & 2.491 & 2.519 & \\
\hline $\mathrm{La}-\mathrm{O}_{\mathrm{PO}_{3}}(1)$ & 2.441 & 2.436 & & 2.408 & 2.437 & \\
\hline $\mathrm{N}_{\mathrm{py}}-\mathrm{La}-\mathrm{N}_{\mathrm{py}}$ & 159.923 & 153.431 & & 158.776 & 154.233 & \\
\hline $\mathrm{O}_{\mathrm{PO}_{3}}-\mathrm{La}-\mathrm{O}_{\mathrm{PO}_{3}}$ & 146.181 & 151.109 & & 146.441 & 152.520 & \\
\hline \multicolumn{7}{|l|}{$\mathrm{Nd}$} \\
\hline $\mathrm{Nd}-\mathrm{N}_{\mathrm{am}}(1)$ & 3.081 & 2.923 & & 3.097 & 2.897 & \\
\hline $\mathrm{Nd}-\mathrm{O}_{\mathrm{PO}_{3}}(1)$ & 2.381 & 2.382 & & 2.347 & 2.379 & \\
\hline $\mathrm{Nd}-\mathrm{O}_{\mathrm{PO}_{3}}(2)$ & 2.350 & 2.371 & & 2.363 & 2.371 & \\
\hline $\mathrm{Nd}-\mathrm{O}_{\mathrm{w}}$ & 2.604 & 2.590 & & 2.601 & 2.576 & \\
\hline $\mathrm{N}_{\mathrm{py}}-\mathrm{Nd}-\mathrm{N}_{\mathrm{py}}$ & 159.219 & 153.485 & & 158.171 & 152.595 & \\
\hline $\mathrm{O}_{\mathrm{PO}_{3}}-\mathrm{Nd}-\mathrm{O}_{\mathrm{PO}_{3}}$ & 146.532 & 151.193 & & 145.996 & 151.377 & \\
\hline \multicolumn{7}{|l|}{$\mathrm{Gd}$} \\
\hline $\mathrm{Gd}-\mathrm{N}_{\mathrm{am}}(1)$ & 3.134 & 2.920 & & 3.158 & 2.881 & \\
\hline $\mathrm{Gd}-\mathrm{N}_{\mathrm{am}}(2)$ & 2.991 & 2.893 & & 3.155 & 2.944 & \\
\hline $\mathrm{Gd}-\mathrm{N}_{\mathrm{py}}(1)$ & 2.805 & 2.665 & & 2.738 & 2.660 & \\
\hline $\mathrm{Gd}-\mathrm{N}_{\mathrm{py}}(2)$ & 2.656 & 2.642 & & 2.647 & 2.644 & \\
\hline $\mathrm{Gd}-\mathrm{OCOO}_{\mathrm{COO}}(1)$ & 2.406 & 2.502 & & 2.412 & 2.521 & \\
\hline $\mathrm{Gd}-\mathrm{O}_{\mathrm{COO}}(2)$ & 2.360 & 2.392 & & 2.356 & 2.386 & \\
\hline \multicolumn{7}{|l|}{ Ho } \\
\hline Ho- $-\mathrm{N}_{\mathrm{am}}(2)$ & 3.027 & 2.909 & & 3.217 & 2.975 & \\
\hline $\mathrm{Ho}-\mathrm{N}_{\mathrm{py}}(1)$ & 2.793 & 2.637 & & 2.721 & 2.631 & \\
\hline $\mathrm{Ho}-\mathrm{N}_{\mathrm{py}}(2)$ & 2.632 & 2.618 & & 2.629 & 2.621 & \\
\hline $\mathrm{Ho}-\mathrm{O}_{\mathrm{COO}}(1)$ & 2.363 & 2.468 & & 2.367 & 2.485 & \\
\hline $\mathrm{Ho}-\mathrm{O}_{\mathrm{COO}}(2)$ & 2.312 & 2.346 & & 2.306 & 2.339 & \\
\hline $\mathrm{Ho}-\mathrm{O}_{\mathrm{PO}_{3}}(1)$ & 2.241 & 2.267 & & 2.232 & 2.272 & \\
\hline $\mathrm{Ho}-\mathrm{O}_{\mathrm{PO}_{3}}(2)$ & 2.268 & 2.278 & & 2.249 & 2.272 & \\
\hline $\mathrm{Ho}-\mathrm{O}_{\mathrm{w}}$ & 2.506 & 2.467 & & 2.497 & 2.462 & \\
\hline $\mathrm{N}_{\mathrm{py}}-\mathrm{Ho}-\mathrm{N}_{\mathrm{py}}$ & 156.140 & 152.711 & & 154.378 & 152.324 & \\
\hline $\mathrm{O}_{\mathrm{PO}_{3}}-\mathrm{Ho}-\mathrm{O}_{\mathrm{PO}_{3}}$ & 145.709 & 149.804 & & 143.138 & 150.160 & \\
\hline \multicolumn{7}{|l|}{$\mathrm{Lu}$} \\
\hline $\mathrm{Lu}-\mathrm{N}_{\mathrm{am}}(1)$ & 3.283 & 2.957 & 3.121 & 3.327 & 2.973 & 3.136 \\
\hline $\mathrm{Lu}-\mathrm{N}_{\mathrm{am}}(2)$ & 3.098 & 2.938 & 2.895 & 3.307 & 3.038 & 2.960 \\
\hline $\mathrm{Lu}-\mathrm{N}_{\mathrm{py}}(1)$ & 2.785 & 2.613 & 2.710 & 2.704 & 2.602 & 2.665 \\
\hline $\mathrm{Lu}-\mathrm{N}_{\mathrm{py}}(2)$ & 2.610 & 2.593 & 2.570 & 2.612 & 2.593 & 2.588 \\
\hline $\mathrm{Lu}-\mathrm{O}_{\mathrm{COO}}(1)$ & 2.308 & 2.425 & 2.274 & 2.310 & 2.426 & 2.272 \\
\hline $\mathrm{Lu}-\mathrm{O}_{\mathrm{COO}}(2)$ & 2.253 & 2.290 & 2.226 & 2.245 & 2.282 & 2.220 \\
\hline $\mathrm{Lu}-\mathrm{O}_{\mathrm{PO}_{3}}(1)$ & 2.212 & 2.225 & 2.190 & 2.193 & 2.215 & 2.181 \\
\hline $\mathrm{Lu}-\mathrm{OPO}_{3}(2)$ & 2.188 & 2.218 & 2.143 & 2.177 & 2.214 & 2.138 \\
\hline $\mathrm{Lu}-\mathrm{O}_{\mathrm{w}}$ & 2.454 & 2.419 & & 2.444 & 2.414 & \\
\hline $\mathrm{N}_{\mathrm{py}}-\mathrm{Lu}-\mathrm{N}_{\mathrm{py}}$ & 153.533 & 151.757 & 160.842 & 151.463 & 151.163 & 160.351 \\
\hline $\mathrm{O}_{\mathrm{PO}_{3}}-\mathrm{Lu}-\mathrm{O}_{\mathrm{PO}_{3}}$ & 144.112 & 148.752 & 163.346 & 140.719 & 148.151 & 162.891 \\
\hline
\end{tabular}

${ }^{a}$ Distances $(\AA)$, angles $\left({ }^{\circ}\right)$. $\mathrm{N}_{\mathrm{am}}=$ amine nitrogen atoms; $\mathrm{N}_{\mathrm{py}}=$ pyridyl nitrogen atoms; $\mathrm{O}_{\mathrm{CoO}}=$ carboxylate oxygen atoms; $\mathrm{O}_{\mathrm{PO}}=$ phosphonate oxygen atoms; $\mathrm{O}_{\mathrm{w}}=$ water oxygen atom. 

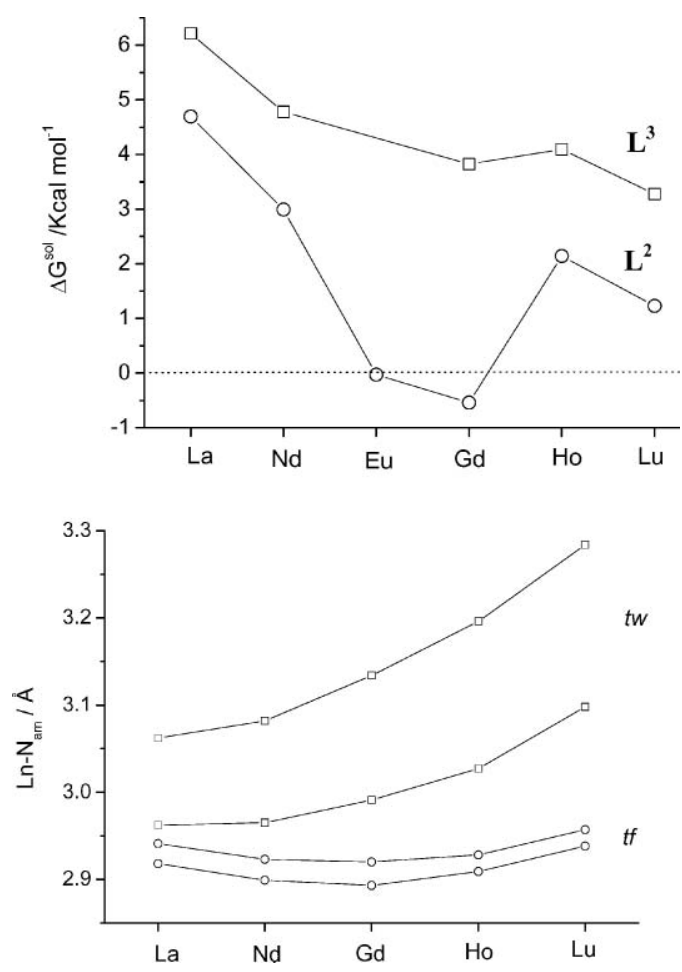

Fig. 5 Top: In aqueous solution (C-PCM) relative free energies of the $t f$ isomer $\left(\Delta G^{\text {sol }}=G^{\text {sol }}{ }_{(t f)}-G^{\text {sol }}{ }_{(t w)}\right)$ for $\left[\operatorname{Ln}(\mathrm{L})\left(\mathrm{H}_{2} \mathrm{O}\right)\right]^{3-}\left(\mathrm{L}=\mathbf{L}^{2}, \mathbf{L}^{3}\right)$ complexes. Bottom: Calculated values of the bond distance between the lanthanide ion and the amine nitrogen atoms $\left(\mathrm{Ln}-\mathrm{N}_{\mathrm{am}}\right)$ in the $t w$ and $t f$ isomers of $\left[\mathrm{Ln}\left(\mathbf{L}^{2}\right)\left(\mathrm{H}_{2} \mathrm{O}\right)\right]^{3-}$ complexes.

the lanthanide series, reaches a minimum with $\mathrm{Gd}$, and then increases for the heaviest lanthanides. The $t w$ form is the most stable along the whole lanthanide series for the $\mathbf{L}^{3}$ complexes, while for those of $\mathbf{L}^{2}$ only the $\mathrm{Gd}^{\mathrm{III}}$ complex is more stable in the $t f$ conformation by $c a$. $0.5 \mathrm{kcal} \mathrm{mol}^{-1}$. The $\mathbf{L}^{3}$ complexes present higher relative energies of the $t w$ conformation than the $\mathbf{L}^{2}$ complexes. The reason is probably the higher flexibility of $\mathbf{L}^{2}$, which allows the folding of the pyridine units relative to each other without increasing importantly the strain of the ligand in the complexes. It is noteworthy that the tf conformation has been observed by ${ }^{1} \mathrm{H}$ NMR for EuL $\mathbf{L}^{3}$. As discussed above, this conformation slowly converts to the thermodynamically stable $t w$ form.

For the $\left[\mathrm{Ln}\left(\mathbf{L}^{3}\right)\left(\mathrm{H}_{2} \mathrm{O}\right)\right]^{3-}$ complexes a third minimum energy geometry has been obtained, in which the cyclohexyl unit adopts twist-boat conformation. The calculated geometries are given in the ESI. $\uparrow$ Calculated relative free energies indicate that the conformational change from chair to twist-boat $(t b)$ provokes an important destabilization of the system: $\Delta G^{\mathrm{sol}}=G^{\mathrm{sol}}{ }_{(t b)}-G^{\mathrm{sol}}{ }_{(t w)}=$ $10.93(\mathrm{Nd}), 4.85(\mathrm{Gd})$ and $6.87 \mathrm{kcal} \mathrm{mol}^{-1}(\mathrm{Lu})$. According to these values, the twist-boat form is less stable than the $t w$ and $t f$ conformations described above.

The variation of the relative energies of the two isomers of $\mathbf{L}^{2}$ and $\mathbf{L}^{3}$ complexes along the lanthanide series appears to be related, at least in part, to the bond distances of the metal coordination environment. Most of the calculated bond distances between the lanthanide and the coordinated donor atoms (Table 3) decrease along the lanthanide series, as usually observed for $\mathrm{Ln}^{\mathrm{III}}$ complexes. ${ }^{34}$ The destabilization of the $t w$ conformation along the first half of the lanthanide series can be attributed to the weakening of the interaction between the $\mathrm{Ln}^{\mathrm{III}}$ ion and the amine nitrogen atoms, since the $\mathrm{Ln}-\mathrm{N}_{\mathrm{am}}$ distances clearly increase along the lanthanide series (Fig. 5). A similar enlargement of Ln-N bond distances has been previously observed for lanthanide complexes with crown ethers, which has been attributed to a better size match between the ligand cavity and the lightest $\mathrm{Ln}^{\mathrm{III}}$ ions. ${ }^{41}$ On the contrary, the $\mathrm{Ln}-\mathrm{N}_{\mathrm{am}}$ distances decrease along the first half of the lanthanide series for the $t f$ form, reaching a minimum with $\mathrm{Gd}^{\mathrm{III}}$, and then increasing for the heaviest lanthanide ions. According to the variation of the $\mathrm{Ln}-\mathrm{N}_{\mathrm{am}}$ bond distances for the $t w$ and $t f$ conformations one expects a maximum stabilization of the $t f$ form for the middle of the lanthanide series.

\section{Second-sphere hydration shell}

Recent studies have demonstrated that due to their charge and important structure ordering effect, phosphonate groups have a tendency to induce a second hydration sphere around the metal complexes. ${ }^{9,10}$ By remaining in the proximity of the paramagnetic $\mathrm{Gd}^{\mathrm{III}}$ center for a non-negligible time, these second sphere water molecules may represent a significant contribution to the overall proton relaxivity of MRI contrast agents. The analysis of the NMRD profiles of phosphonic acid derivatives of diethylenetriamine suggested the presence of two second sphere water molecules contributing to the overall proton relaxivity. ${ }^{9}$

The $a b$ initio calculations presented here provide useful direct information about the second sphere solvation shell. The calculations on molecular clusters $\left[\mathrm{Gd}(\mathrm{L})\left(\mathrm{H}_{2} \mathrm{O}\right)\right]^{3-} \cdot 19 \mathrm{H}_{2} \mathrm{O}$ indicate that most of the second sphere water molecules are hydrogen bonded to the highly charged phosphonate groups. The distances between the $\mathrm{Gd}^{\mathrm{III}}$ ion and the oxygen and hydrogen atoms of second sphere water molecules hydrogen bonded to the phosphonate groups are given in Table S1 (ESI $\dagger$ ). Our calculations indicate that at least six or seven water molecules are hydrogen-bonded to each phosphonate group. For the complexes in $t w$ conformation only three second sphere water molecules are in close proximity of the $\mathrm{Gd}^{\mathrm{III}}$ ion with $\mathrm{Gd}-\mathrm{O}$ distances of $4.1-4.2 \AA$, whereas the other second-sphere water molecules are relatively distant (GdO distances above $5.4 \AA$ ). Among the three water molecules close to the $\mathrm{Gd}^{\mathrm{III}}$ ion two are hydrogen bonded to the phosphonate group situated close to the inner sphere water molecule (Fig. 4), while the third one is interacting with the second (more sterically crowded) phosphonate group. A similar situation occurs for the $[\mathrm{Lu}(\mathrm{L})]^{3-}$ systems, which show two second sphere water molecules in the close proximity of the $\mathrm{Lu}^{\mathrm{III}}$ ion with $\mathrm{Lu}-\mathrm{O}$ distances of 3.9$4.0 \AA$, and a third water molecule showing an intermediate $\mathrm{Lu}-\mathrm{O}$ distance ( $c a .4 .6 \AA)$. The remaining second sphere water molecules are relatively far from the lanthanide ion. Since both ${ }^{1} \mathrm{H}$ and ${ }^{17} \mathrm{O}$ longitudinal relaxation rates depend on $1 / r^{6}$, where $r$ represents the distance between the observed nucleus and the $\mathrm{Gd}^{\mathrm{III}}$ ion, ${ }^{42}$ only water molecules relatively close to the paramagnetic centre are expected to provide a substantial second sphere contribution. Thus, it appears reasonable to assume three second sphere water molecules in the analysis of the relaxivity and ${ }^{17} \mathrm{O}$ NMRD data of the $\mathrm{Gd}^{\mathrm{III}}$ complexes with $\mathbf{L}^{2}$ and $\mathbf{L}^{3}{ }^{8}$ In contrast to the $t w$ conformation in the $t f$ form all three closely situated second sphere 
water molecules are hydrogen-bonded to one of the phosphonate groups, for steric reasons.

\section{${ }^{13} \mathrm{C}$ NMR shielding constants}

It has been demonstrated that quantum-mechanical GIAO calculations of ${ }^{13} \mathrm{C} \mathrm{NMR}$ chemical shifts can be used as a tool for structure validation of coordination compounds, ${ }^{43}$ including lanthanide complexes. ${ }^{36,44}$ Thus, the ${ }^{13} \mathrm{C}$ NMR shielding constants of the $t w$ and $t f$ forms of the $\left[\mathrm{La}(\mathrm{L})\left(\mathrm{H}_{2} \mathrm{O}\right)\right]^{3-}\left(\mathrm{L}=\mathbf{L}^{2}, \mathbf{L}^{3}\right)$ complexes were calculated on the in vacuo optimized structures of $\left[\mathrm{La}(\mathrm{L})\left(\mathrm{H}_{2} \mathrm{O}\right)\right]^{3-} \cdot 19 \mathrm{H}_{2} \mathrm{O}$ by using the GIAO method. Due to the importance of including electronic correlation effects the calculations of the NMR shielding constants were performed at the B3LYP/6-311G** level, by using the 46 core electron ECP by Stevens et al. $^{20}$ In these calculations solvent effects (water) were included by using the C-PCM model. The calculated ${ }^{13} \mathrm{C}$ NMR shifts are compared with the experimental values in Table 4 . We notice a systematic deviation to lower fields of the calculated values with respect to the experimental ones. Thus, in order to asses the agreement between the experimental and calculated ${ }^{13} \mathrm{C} N \mathrm{NM}$ spectra, we have plotted the experimental ${ }^{13} \mathrm{C}$ chemical shift values $v s$. the corresponding GIAO calculated ${ }^{13} \mathrm{C}$ chemical shifts for the $t w$ and $t f$ isomers. These plots give straight lines whose slopes and intercepts are given in Table 4 . The correlation plots obtained for the complexes of $\mathbf{L}^{3}$ are shown in Fig. 6. In general, the linear correlation of these plots is better for the $t w$ than for the $t f$ form in both $\mathbf{L}^{2}$ and $\mathbf{L}^{3}$ complexes, as indicated by the $R^{2}$ values obtained from the linear least squares fit. This implies that the $t f$ form is a less probable structure of the complexes in solution. To confirm this we have calculated scaled theoretical chemical shift values $\left(\delta_{i}\right.$, esc $)$ obtained as: $:^{45}$

$$
\delta_{i, \text { esc }}=\left(\delta_{i, \text { calc }}-A\right) / B
$$

where $\delta_{i}$,calc are the GIAO calculated chemical shifts, and $A$ and $B$ are the intercept and slope obtained from the linear correlation plots of the same compound. Fig. 6 shows a plot of differences between experimental and scaled theoretical ${ }^{13} \mathrm{C}$ NMR shift values
$(\Delta \delta)$ for the $t w$ and $t f$ complexes of $\mathbf{L}^{3}$ obtained at the B3LYP/6$311 \mathrm{G}^{* *}$ level, where it is possible to appreciate larger deviations from the experimental values for most carbon nuclei of the $t f$ form than for the same nuclei in the $t w$ one. An analogous analysis of the scaled theoretical shifts calculated for the complex of $\mathbf{L}^{2}$ leads to similar conclusions. These results therefore confirm that the $\mathrm{La}^{\mathrm{III}}$ complexes of $\mathbf{L}^{2}$ and $\mathbf{L}^{3}$ are present in solution in $t w$ conformation, in agreement with the relative free energies of the two isomers discussed above.

\section{$\mathrm{Nd}^{\mathrm{III}}$-Induced relaxation rate enhancement effects}

Information on the solution structure of the complexes was obtained from $\mathrm{Nd}^{\mathrm{III}}$-induced relaxation rate enhancements of the ${ }^{1} \mathrm{H}$ nuclei of ligands $\mathbf{L}^{2}$ and $\mathbf{L}^{3}$. Among the lighter $\operatorname{Ln}^{\mathrm{III}}$ ions $(\mathrm{Ln}=$ $\mathrm{Ce} \rightarrow \mathrm{Eu}), \mathrm{Nd}^{\mathrm{III}}$ has the longest electron relaxation times, ${ }^{46,47}$ and therefore this cation is very suitable for obtaining structural information of lanthanide complexes in solution. ${ }^{48}$ The $\mathrm{Nd}^{\text {III }}$ induced ${ }^{1} \mathrm{H}$ NMR relaxation enhancements for both ligands were measured at $7.05 \mathrm{~T}$ and $25{ }^{\circ} \mathrm{C}$ (Table 5). In order to correct for diamagnetic contributions, the relaxation rates for the corresponding $\mathrm{La}^{\mathrm{III}}$ complex were subtracted from the measured values of the $\mathrm{Nd}^{\text {III }}$ complex (see Table 5).

Since the outer-sphere contribution $\left(1 / T_{\text {los }}\right)$ becomes significant only for remote nuclei, this contribution was neglected. The electron relaxation for $\mathrm{Nd}^{\mathrm{III}}$ is very fast $\left(T_{1 \mathrm{e}} \approx 10^{-13} \mathrm{~s}\right)$ and, consequently, the contact contribution to the paramagnetic relaxation is negligible. Two contributions are of importance: the "classical" dipolar relaxation and the Curie relaxation. Eqn (5) can be derived from a simplified Solomon-Bloembergen equation ${ }^{49}$ and from the equation for the Curie relaxation (assuming extreme narrowing): $: 50,51$

$$
\frac{1}{T_{1}}=\left[4 / 3\left(\frac{\mu_{0}}{4 \pi}\right)^{2} \mu^{2} \gamma_{1}^{2} \beta^{2} t_{1 \mathrm{e}}+6 / 5\left(\frac{\mu_{0}}{4 \pi}\right)^{2} \frac{\gamma_{2}^{1} H_{0}^{2} \mu^{4} \beta^{4}}{(3 k T)^{2}} \tau_{\mathrm{R}}\right] \frac{1}{r^{6}}
$$

Table 4 Experimental ${ }^{13} \mathrm{C}$ shifts (ppm) for the $\mathrm{La}^{\mathrm{III}}$ complexes of $\mathbf{L}^{2}$ and $\mathbf{L}^{3}$ in $30 \mathrm{mM} \mathrm{D} \mathrm{D}_{2} \mathrm{O}$ solutions at $\mathrm{pH} 7.6$ and calculated (GIAO method) ${ }^{13} \mathrm{C}$ NMR

\begin{tabular}{|c|c|c|c|c|c|c|}
\hline & \multicolumn{3}{|l|}{$\mathbf{L}^{2}$} & \multicolumn{3}{|l|}{$\mathbf{L}^{3}$} \\
\hline & $\delta_{i, \text { exptl }}$ & $\delta_{i, \operatorname{calc}(t w)}$ & $\delta_{i, \operatorname{calc}(t f)}$ & $\delta_{i, \text { exptl }}$ & $\delta_{i, \text { calct }(t w)}$ & $\delta_{i, \operatorname{calc}(t f)}$ \\
\hline 1 & 175.1 & 178.2 & 179.1 & 175.0 & 178.2 & 179.2 \\
\hline 2 & 153.1 & 156.9 & 157.8 & 152.7 & 157.1 & 157.9 \\
\hline 3 & 124.9 & 127.6 & 127.4 & 124.8 & 127.7 & 127.3 \\
\hline 4 & 141.4 & 143.8 & 144.2 & 141.5 & 143.7 & 144.0 \\
\hline 5 & 127.6 & 130.2 & 129.8 & 128.2 & 131.0 & 130.3 \\
\hline 6 & 159.4 & 167.6 & 168.4 & 159.6 & 168.5 & 169.1 \\
\hline 7 & 62.5 & 67.5 & 69.3 & 58.0 & 62.7 & 64.3 \\
\hline 8 & 57.2 & 59.4 & 63.0 & 52.6 & 55.0 & 57.1 \\
\hline 9 & 55.4 & 58.7 & 59.8 & 63.2 & 66.2 & 64.2 \\
\hline 10 & & & & 24.8 & 28.8 & 27.1 \\
\hline 11 & & & & 26.3 & 31.7 & 25.0 \\
\hline$R^{2 a}$ & & 0.9992 & 0.998 & & 0.9994 & 0.9990 \\
\hline$A^{a}$ & & $2.6 \pm 1.9$ & $5.4 \pm 2.2$ & & $3.7 \pm 1.3$ & $1.1 \pm 1.7$ \\
\hline$B^{a}$ & & $1.01 \pm 0.01$ & $0.99 \pm 0.02$ & & $1.00 \pm 0.01$ & $1.02 \pm 0.02$ \\
\hline
\end{tabular}
chemical shift values for the $t w$ and $t f$ conformations (see Scheme 1 for labelling)

${ }^{a}$ Intercept, slope and correlation coefficient obtained by linear fitting of calculated $v s$. experimental ${ }^{13} \mathrm{C}$ NMR chemical shift plots (see text). 

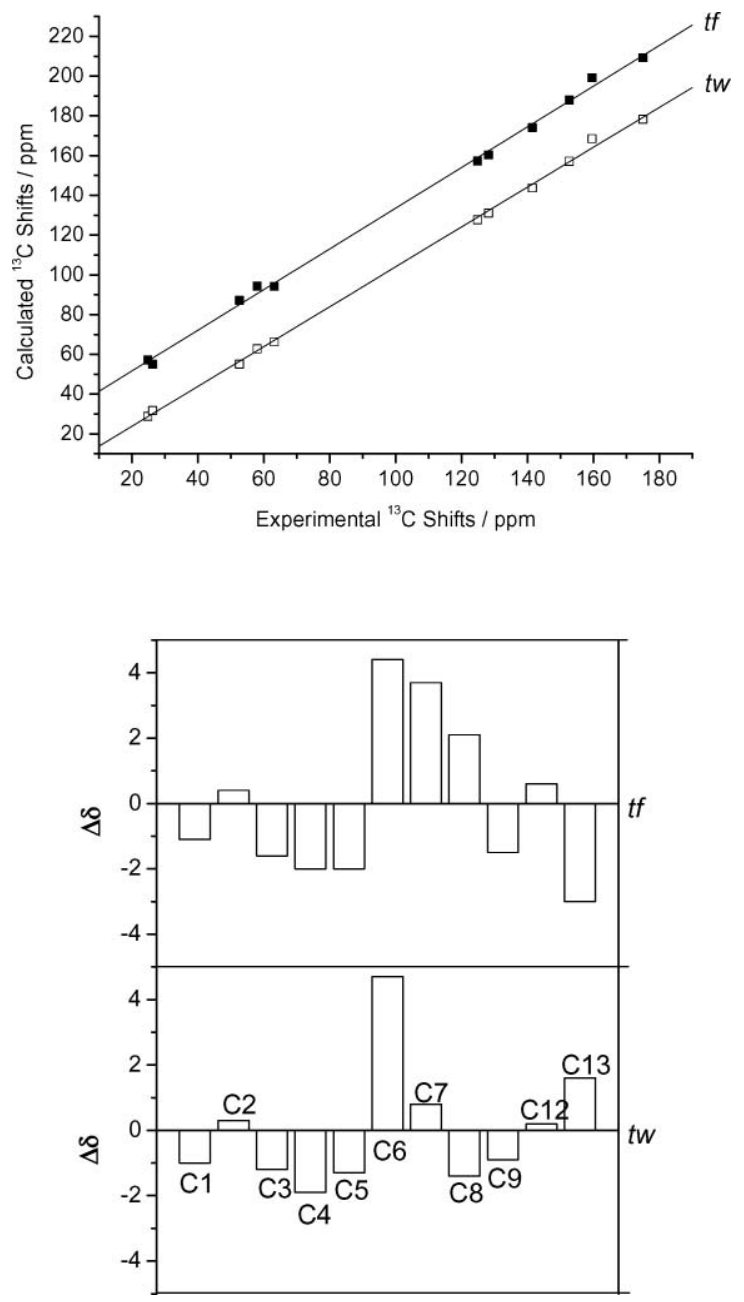

Fig. 6 Top: data points and fitting straight lines of calculated $v s$. experimental ${ }^{13} \mathrm{C}$ NMR chemical shifts at the B3LYP/6-311G** level for the $t w$ and $t f$ structures of $\left[\mathrm{La}\left(\mathbf{L}^{3}\right)\left(\mathrm{H}_{2} \mathrm{O}\right)\right]^{3-}$ complexes in aqueous solution. The plot relative to $t f$ has been displaced by $30 \mathrm{ppm}$ along the ordinate axis for better visualization. Bottom: Differences between experimental and scaled theoretical ${ }^{13} \mathrm{C}$ NMR chemical shifts (B3LYP/6-311G** level) for the $t w$ and $t f$ isomers of $\left[\mathrm{La}\left(\mathbf{L}^{3}\right)\left(\mathrm{H}_{2} \mathrm{O}\right)\right]^{3-}$.

where the first term between the square brackets represents the "classical" dipolar contribution, and the second term describes the Curie relaxation. Here, $\mu_{0} / 4 \pi$ is the magnetic permeability in a vacuum, $\mu$ is the effective magnetic moment of the lanthanide ion, $\gamma_{I}$ is the gyromagnetic ratio of the nucleus under study, $\beta$ is the Bohr magneton, $T_{1 \mathrm{e}}$ is the electron spin relaxation time, $r$ is the distance between the ${ }^{1} \mathrm{H}$ nucleus in question and the lanthanide ion, $H_{0}$ is the magnetic field strength, $k$ is the Boltzmann constant, $T$ is the temperature, and $\tau_{\mathrm{R}}$ is the rotational tumbling time of the complex. The contribution of the Curie spin mechanism to the total relaxation becomes significant for larger molecules $\left(\tau_{\mathrm{R}}\right.$ increases), particularly at higher fields.

At constant temperature and $B_{0}$, application of eqn (5) allows the determination of relative $r$ values in the complexes without the need to estimate $T_{1 \mathrm{e}}$ and $\tau_{\mathrm{R}}$, which would be needed to calculate absolute distances. Plots of $1 / T_{1} v s .1 / r^{6}$, where $r$ stands for the $\mathrm{Nd} \cdot \cdot \mathrm{H}$ distances obtained from the ab initio optimized structures give straight lines $\left(R^{2}>0.996\right)$ passing through the origin with
Table 5 Relaxation rates $\left(\mathrm{s}^{-1}\right)$ determined for $40 \mathrm{mM}$ solutions of $\mathrm{Ln}^{\mathrm{III}}$ complexes in $\mathrm{D}_{2} \mathrm{O}\left(300 \mathrm{MHz}, 25^{\circ} \mathrm{C}, \mathrm{pH}=7.6\right)$ and $\mathrm{Nd} \cdots \mathrm{H}$ distances $(\AA)$ calculated from ${ }^{1} \mathrm{H}$ NMR relaxation data

\begin{tabular}{|c|c|c|c|c|c|c|c|c|}
\hline & \multicolumn{2}{|l|}{$1 / T_{1(\mathrm{Nd})}$} & \multicolumn{2}{|c|}{$1 / T_{1(\mathrm{La})}$} & \multicolumn{2}{|c|}{$\begin{array}{l}\mathrm{Nd} \cdots \mathrm{H} \\
(\text { Calc. })^{b}\end{array}$} & \multicolumn{2}{|c|}{$\begin{array}{l}\mathrm{Nd} \cdots \mathrm{H} \\
(\text { Exptl.) }\end{array}$} \\
\hline & $\mathbf{L}^{2}$ & $\mathbf{L}^{3}$ & $\overline{L^{2}}$ & $\mathbf{L}^{3}$ & $\overline{\mathbf{L}^{2}}$ & $\mathbf{L}^{3}$ & $\overline{\mathbf{L}^{2}}$ & $\mathbf{L}^{3}$ \\
\hline H3 & 9.221 & 8.718 & 0.683 & 0.524 & 5.600 & 5.572 & 5.89 & 5.63 \\
\hline H4 & 4.384 & 4.337 & 0.756 & 0.524 & 6.562 & 6.529 & 6.79 & 6.26 \\
\hline H5 & 8.454 & 8.326 & 0.914 & 1.294 & 5.799 & 5.762 & 6.02 & 5.75 \\
\hline H7ax & 95.111 & 75.896 & 3.650 & 6.976 & 3.997 & 3.989 & 3.97 & 4.02 \\
\hline H7eq & 27.054 & $a$ & 4.0 & 5.786 & 4.764 & 4.766 & 4.99 & $a$ \\
\hline $\mathrm{H} 8 \mathrm{a}$ & 102.135 & $a$ & 3.630 & 4.086 & 3.946 & 3.868 & 3.92 & $a$ \\
\hline $\mathrm{H} 8 \mathrm{~b}$ & 29.619 & 28.490 & 3.057 & 5.814 & 4.727 & 4.7 & 4.88 & 4.81 \\
\hline H9ax & 86.08 & 66.05 & 3.481 & 3.519 & 4.015 & 4.137 & 4.04 & 4.08 \\
\hline H9eq & $a$ & & 4.552 & & 4.823 & & $a$ & \\
\hline $\mathrm{H} 10$ & & 14.95 & & 7.196 & & 5.634 & & 5.67 \\
\hline H10' & & 13.038 & & 6.954 & & 5.767 & & 5.87 \\
\hline H11 & & 8.423 & & $a$ & & 6.641 & & $a$ \\
\hline H1 $1^{\prime}$ & & 6.798 & & 5.519 & & 7.471 & & 7.06 \\
\hline
\end{tabular}

${ }^{a}$ Not obtained. ${ }^{b} \mathrm{Nd}^{\mathrm{III}} \cdots \mathrm{H}$ distances obtained from $a b$ initio calculations ( $t w$ conformations). ${ }^{c} \mathrm{Nd}^{\mathrm{III}} \cdots \mathrm{H}$ distances obtained from experimental ${ }^{1} \mathrm{H}$ NMR relaxation data.

slopes $k=(3.57 \pm 0.09) \times 10^{-55} \mathrm{~m}^{6} \mathrm{~s}^{-1}\left(\mathbf{L}^{2}\right)$ and $k=(2.88 \pm 0.07) \times$ $10^{-55} \mathrm{~m}^{6} \mathrm{~s}^{-1}\left(\mathbf{L}^{3}\right)$. The slope obtained from this plot represents the term between the brackets in eqn (5). Using the $\tau_{\mathrm{R}}$ obtained from ${ }^{2} \mathrm{H}$ NMR relaxation data at a concentration of $40 \mathrm{mM}\left(\tau_{\mathrm{R}}=\right.$ $152 \mathrm{ps})^{8}$ we obtain $T_{1 \mathrm{e}}=2.69 \times 10^{-13} \mathrm{~s}$ for the $\mathbf{L}^{2}$ complex, a value substantially longer than the one determined by Alsaadi et al. for the aqua ion $\left(T_{\mathrm{le}}=1.15 \times 10^{-13} \mathrm{~s}\right) .^{52}$ The experimental values of $k$ were used to obtain experimental $\mathrm{Nd}^{\mathrm{III}} \cdots \mathrm{H}$ distances in solution from relaxation data by using eqn (5). In general, the experimental distances are in satisfactory agreement with those obtained from the theoretical calculations (Table 5), thereby confirming that the computational approach provides a reliable description of the solution structures.

\section{Conclusions}

The octadentate ligands $\mathbf{L}^{2}$ and $\mathbf{L}^{3}$ form thermodynamically stable $\mathrm{Gd}^{\mathrm{III}}$ complexes in aqueous solution, and thus can be considered as new basic structural frameworks for the design of novel MRI contrast agents. Our results show an improved stability of the $\mathrm{Gd}^{\mathrm{III}}$ complexes in aqueous solution when the acetate arms of $\mathbf{L}^{1}$ are replaced by phosphonate pendants. NMR studies in solution indicate octadentate binding of $\mathbf{L}^{2}$ and $\mathbf{L}^{3}$ to the $\mathrm{Ln}^{\mathrm{III}}$ ions. Quantum mechanical calculations performed at the HF level provide two minimum energy geometries of the complexes where the ligand adopts different conformations: twist-wrap $(t w)$, in which the ligand wraps around the metal ion by twisting the pyridyl units relative to each other, and twist-fold $(t f)$, where the slight twisting of the pyridyl units is accompanied by an overall folding of the two pyridine units towards one of the phosphonate groups. The $t w$ form is the most stable one along the whole lanthanide series for the complexes of $\mathbf{L}^{3}$, while for those of $\mathbf{L}^{2}$ only the $\mathrm{Gd}^{\mathrm{III}}$ complex is more stable in the $t f$ conformation by $c a$. $0.5 \mathrm{kcal} \mathrm{mol}^{-1}$. Our results indicate that the relative energy of the tf conformation decreases along the first half of the lanthanide series, reaches a minimum with $\mathrm{Gd}$, then increases for the heaviest lanthanides. ${ }^{1} \mathrm{H}$ NMR studies of $\mathrm{Eu}^{3}$ show the initial formation 
of the $t f$ complex in aqueous solution, which slowly converts to the thermodynamically stable $t w$ form. The calculated structures for the $\mathrm{Nd}^{\mathrm{III}}$ complexes are in reasonably good agreement with the experimental solution structures, as demonstrated by $\mathrm{Nd}^{\mathrm{III}}$ induced relaxation rate enhancement effects in the ${ }^{1} \mathrm{H}$ NMR spectra. The computational approach presented in this work, in combination with experimental information obtained by NMR spectroscopy, represents a powerful tool to obtain structural information of lanthanide complexes in solution.

\section{Acknowledgements}

M. M.-I, C. P.-I., A. de B. and T. R-B. thank Ministerio de Ciencia y Tecnología and FEDER (BQU2001-0796), Xunta de Galicia (PGIDIT02PXI10301PN) and Universidade da Coruña for financial support. É. T. and E. B. thank the Swiss National Science Foundation and the Swiss State Secretariat for Education and Research (SER) for financial support. This research was performed in the framework of the EU COST Action D18 "Lanthanide Chemistry for Diagnosis and Therapy", and the European-founded EMIL program (LSCH-2004-503569); their support and sponsorship is also kindly acknowledged. The authors are indebted to Centro de Supercomputación of Galicia (CESGA) for providing the computer facilities.

\section{References}

1 D. Parker, R. S. Dickins, H. Puschmann, C. Crossland and J. A. K. Howard, Chem. Rev., 2002, 102, 1977.

2 The Chemistry of Contrast Agents in Medical Magnetic Resonance Imaging, ed. A. E. Mebach and É. Tóth, Wiley, New York, 2001.

3 P. Caravan, J. J. Ellinson, T. J. McMurry and R. B. Lauffer, Chem. Rev., 1999, 99, 2293.

4 D. Parker, Coord. Chem. Rev., 2000, 205, 109.

5 C. Platas-Iglesias, M. Mato-Iglesias, K. Djanashvili, R. N. Muller, L. Vander Elst, J. A. Peters, A. de Blas and T. Rodríguez-Blas, Chem. Eur. J., 2004, 10, 3579.

6 N. Chatterton, C. Gateau, M. Mazzanti, J. Pécaut, A. Borel, L. Helm and A. E. Merbach, Dalton Trans., 2005, 1129.

7 M. Mato-Iglesias, C. Platas-Iglesias, K. Djanashvili, J. A. Peters, É. Tóth, E. Balogh, R. N. Muller, L. Vander Elst, A. de Blas and T. Rodríguez-Blas, Chem. Commun., 2005, 4729.

8 E. Balogh, M. Mato-Iglesias, C. Platas-Iglesias, É. Tóth, K. Djanashvili, J. A. Peters, A. de Blas and T. Rodríguez-Blas, Inorg. Chem., 2006, 45, 8719.

9 J. Kotek, P. Lebdušková, P. Hermann, L. Vander Elst, R. N. Muller, C. F. G. C. Geraldes, T. Maschmeyer, I. Lukeš and J. A. Peters, Chem. Eur. J., 2003, 9, 5899.

10 S. Aime, E. Gianolio, D. Corpillo, C. Cavallotti, M. Palmisano, M Sisti, G. B. Giovenzana and R. Pagliarin, Helv. Chim. Acta, 2003, 86, 615.

11 R. L. Vold, J. S. Waugh, M. P. Klein and D. E. Phelps, J. Chem. Phys, $1968,48,3831$.

12 (a) K. Mikkelsen and S. O. Nielsen, J. Phys. Chem., 1960, 64, 632; (b) P. K. Glasoe and F. A. Long, J. Phys. Chem., 1960, 64, 188.

13 H. M. Irving, M. G. Miles and L. Pettit, Anal. Chim. Acta, 1967, 28, 475.

14 L. Zékány and I. Nagypál, In Computation Methods for Determination of Formation Constants, ed. D. J. Leggett, Plenum, New York, 1985, p. 291.

15 M. Dolg, H. Stoll, A. Savin and H. Preuss, Theor. Chim. Acta, 1989, 75, 173 .

16 (a) A. D. Becke, J. Chem. Phys., 1993, 98, 5648; (b) C. Lee, W. Yang and R. G. Parr, Phys. Rev. B: Condens. Matter, 1988, 37, 785.

17 V. Barone and M. Cossi, J. Phys. Chem. A, 1998, 102, 1995.

18 U. Cosentino, A. Villa, D. Pitea, G. Moro and V. Barone, J. Phys. Chem $B, 2000,104,8001$.
19 R. Ditchfield, Mol. Phys., 1974, 27, 789.

20 W. J. Stevens, M. Krauss, H. Basch and P. G. Jaisen, Can. J. Chem., $1992,70,612$.

21 T. R. Cundari and W. Stevens, J. Chem. Phys., 1993, 98, 5555.

22 M. J. Frisch, G. W. Trucks, H. B. Schlegel, G. E. Scuseria, M. A. Robb, J. R. Cheeseman, V. G. Zakrzewski, J. A. Montgomery, Jr., R. E. Stratmann, J. C. Burant, S. Dapprich, J. M. Millam, A. D. Daniels, K. N. Kudin, M. C. Strain, O. Farkas, J. Tomasi, V. Barone, M. Cossi, R. Cammi, B. Mennucci, C. Pomelli, C. Adamo, S. Clifford, J. Ochterski, G. A. Petersson, P. Y. Ayala, Q. Cui, K. Morokuma, P. Salvador, J. J. Dannenberg, D. K. Malick, A. D. Rabuck, K. Raghavachari, J. B. Foresman, J. Cioslowski, J. V. Ortiz, A. G. Baboul, B. B. Stefanov, G. Liu, A. Liashenko, P. Piskorz, I. Komaromi, R. Gomperts, R. L. Martin, D. J. Fox, T. Keith, M. A. Al-Laham, C. Y. Peng, A. Nanayakkara, M. Challacombe, P. M. W. Gill, B. G. Johnson, W. Chen, M. W. Wong, J. L. Andres, C. Gonzalez, M. HeadGordon, E. S. Replogle and J. A. Pople, GAUSSIAN 98 (Revision A.11), Gaussian, Inc., Pittsburgh, PA, 2001.

23 M. J. Frisch, G. W. Trucks, H. B. Schlegel, G. E. Scuseria, M. A. Robb, J. R. Cheeseman, J. A. Montgomery, Jr., T. Vreven, K. N. Kudin, J. C. Burant, J. M. Millam, S. S. Iyengar, J. Tomasi, V. Barone, B. Mennucci, M. Cossi, G. Scalmani, N. Rega, G. A. Petersson, H. Nakatsuji, M. Hada, M. Ehara, K. Toyota, R. Fukuda, J. Hasegawa, M. Ishida, T. Nakajima, Y. Honda, O. Kitao, H. Nakai, M. Klene, X. Li, J. E. Knox, H. P. Hratchian, J. B. Cross, V. Bakken, C. Adamo, J. Jaramillo, R. Gomperts, R. E. Stratmann, O. Yazyev, A. J. Austin, R. Cammi, C. Pomelli, J. Ochterski, P. Y. Ayala, K. Morokuma, G. A. Voth, P. Salvador, J. J. Dannenberg, V. G. Zakrzewski, S. Dapprich, A. D. Daniels, M. C. Strain, O. Farkas, D. K. Malick, A. D. Rabuck, K. Raghavachari, J. B. Foresman, J. V. Ortiz, Q. Cui, A. G. Baboul, S. Clifford, J. Cioslowski, B. B. Stefanov, G. Liu, A. Liashenko, P. Piskorz, I. Komaromi, R. L. Martin, D. J. Fox, T. Keith, M. A. Al-Laham, C. Y. Peng, A. Nanayakkara, M. Challacombe, P. M. W. Gill, B. G. Johnson, W. Chen, M. W. Wong, C. Gonzalez and J. A. Pople, GAUSSIAN 03 (Revision C.1), Gaussian, Inc., Wallingford, CT, 2004.

24 V. Markaeva, S. Limikov and Y. Kyrianov, Zh. Neorg. Khim., 1997, 42, 638.

25 A. D. Sherry, J. Ren, J. Huskens, E. Brücher, É. Tóth, C. F. G. C. Geraldes, M. M. C. A. Castro and W. P. Chacheris, Inorg. Chem., 1996, 35, 4604

26 I. Lazar, R. Ramasamy, E. Brücher, C. F. G. C. Geraldes and A. D. Sherry, Inorg. Chim. Acta, 1992, 195, 89.

27 I. Lazar, A. D. Sherry, R. Ramasamy, E. Brücher and R. Kiraly, Inorg. Chem., 1991, 30, 5016.

28 (a) C. Broan, J. P. L. Cox, A. S. Craig, R. Kataky, D. Parker, A. Harrison, A. M. Randall and G. Ferguson, J. Chem. Soc., Perkin Trans. 2, 1991, 87; (b) J. P. L. Cox, K. J. Jankowski, R. Kataky, D. Parker, N. R. A. Beeley, B. A. Boyce, M. A. W. Eaton, K. Millar, A. T. Millican, A. Harrison and C. J. Walker, J. Chem. Soc., Chem. Commun., 1989, 797.

29 K. Kumar, C. A. Chang and M. F. Tweedle, Inorg. Chem., 1993, 32, 587.

30 E. Brücher and A. D. Sherry, Stability and Toxicity of Contrast Agents, in The Chemistry of Contrast Agents in Medical Magnetic Resonance Imaging, ed. E. Tóth and A. E. Merbach, Wiley, Chichester, 2001, p. 243.

31 J. Kotek, F. K. Kálmán, P. Hermann, E. Brücher, K. Binnemans and I. Lukes, Eur. J. Inorg. Chem., 2006, 1976.

32 C. F. G. C. Geraldes, A. D. Sherry and G. E. Kiefer, J. Magn. Reson., 1992, 97, 290.

33 R. K. Harris, Nuclear Magnetic Resonance Spectroscopy: A Physicochemical view, Pitman, London, 1983.

34 C. Platas, F. Avecilla, A. de Blas, C. F. G. C. Geraldes, T. RodríguezBlas, H. Adams and J. Mahía, Inorg. Chem., 1999, 38, 3190.

35 U. Cosentino, G. Moro, D. Pitea, A. Villa, P. C. Fantucci, A. Maiocchi and F. Uggeri, J. Phys. Chem. A, 1998, 102, 4606.

36 U. Cosentino, A. Villa, D. Pitea, G. Moro, V. Barone and A. Maiocchi, J. Am. Chem. Soc., 2002, 124, 4901.

37 N. Quali, B. Bocquet, S. Rigault, P.-Y. Morgantini, J. Weber and C. Piguet, Inorg. Chem., 2002, 41, 1436.

38 S. Tsushima, T. Yang, Y. Mochizuki and Y. Okamoto, Chem. Phys. Lett., 2003, 375, 204.

39 U. Cosentino, G. Moro, D. Pitea, V. Barone, A. Villa, R. N. Muller and F. Botteman, Theor: Chem. Acc., 2004, 111, 204.

40 H. Erras-Hanauer, T. Clark and R. van Eldik, Coord. Chem. Rev., 2003, 238-239, 233. 
41 C. Platas, F. Avecilla, A. de Blas, T. Rodríguez-Blas, R. Bastida, A. Macías, A. Rodríguez and H. Adams, J. Chem. Soc., Dalton Trans., 2001, 1699.

42 J. A. Peters, J. Huskens and D. J. Raber, Prog. Nucl. Magn. Reson. Spectrosc., 1996, 28, 283.

43 C. Platas-Iglesias, D. Esteban, V. Ojea, F. Avecilla, A. de Blas and T. Rodríguez-Blas, Inorg. Chem., 2003, 42, 4299.

44 M. Gonzalez-Lorenzo, C. Platas-Iglesias, F. Avecilla, S. Faulkner, S. J. A. Pope, A. de Blas and T. Rodriguez-Blas, Inorg. Chem., 2005, 44, 4254.

45 G. Barone, L. Gomez-Paloma, D. Duca, A. Silvestre, R. Riccio and G. Bifulco, Chem. Eur. J., 2002, 8, 3233.
46 B. M. Alsaadi, F. J. C. Rossotti and R. J. P. Williams, J. Chem. Soc., Dalton Trans., 1980, 2151.

47 I. Bertini, F. Capozzi, C. Luchinat, G. Nicastro and Z. Xia, J. Phys. Chem., 1993, 97, 6351.

48 H. Lammers, F. Maton, D. Pubanz, M. W. van Laren, H. van Bekkum, A. E. Merbach, R. N. Muller and J. A. Peters, Inorg. Chem., 1997, 36, 2527.

49 J. Reuben and D. Fiat, J. Chem. Phys., 1969, 51, 4918.

50 M. Gueron, J. Magn. Reson., 1975, 19, 58.

51 A. J. Vega and D. Fiat, Mol. Phys., 1976, 31, 347.

52 B. M. Alsaadi, F. J. C. Rossotti and R. J. P. Williams, J. Chem. Soc., Dalton Trans., 1980, 2147. 